\title{
The COVID-19 Vaccine Preference for Youngsters Using PROMETHEE-II in the IFSS Environment
}

\author{
Samayan Narayanamoorthy ${ }^{1} \mathbb{D}$, Subramaniam Pragathi ${ }^{1}$, Thirumalai Nallasivan Parthasarathy ${ }^{1}$, \\ Samayan Kalaiselvan ${ }^{2}$, Joseph Varghese Kureethara ${ }^{3}\left(\mathbb{D}\right.$, Ranganathan Saraswathy ${ }^{4}$, Poosamani Nithya ${ }^{5}$ and \\ Daekook Kang ${ }^{6, *}$
}

\section{check for} updates

Citation: Narayanamoorthy, S.; Pragathi, S.; Parthasarathy, T.N.; Kalaiselvan, S.; Kureethara, J.V.; Nithya, P.; Saraswathy, P.; Kang, D. The COVID-19 Vaccine Preference for Youngsters Using PROMETHEE-II in the IFSS Environment. Symmetry 2021, 13, 1030. httpsg//doi.org/10.3390/ sym13061030

Academic Editor: José Carlos R. Alcantud

Received: 7 May 2021

Accepted: 31 May 2021

Published: 8 June 2021

Publisher's Note: MDPI stays neutral with regard to jurisdictional claims in published maps and institutional affiliations.

Copyright: (c) 2021 by the authors Licensee MDPI, Basel, Switzerland. This article is an open access article distributed under the terms and conditions of the Creative Commons Attribution (CC BY) license (https:/ / creativecommons.org/licenses/by/ $4.0 /)$.
1 Department of Mathematics, Bharathiar University, Coimbatore 641046, Tamil Nadu, India; snmphd@buc.edu.in (S.N.); pragathisubramaniam@gmail.com (S.P.); psarathy751@gmail.com (T.N.P.)

2 Department of Social Work, Sri Ramakrishna Mission Vidyalaya College of Arts and Science, SRMV, Coimbatore 641020, Tamil Nadu, India; skalaiselvan43@gmail.com

3 CHRIST (Deemed to Be University), Bangalore 560029, Karnataka, India; frjoseph@christuniversity.in

4 Karpagam Medical College and Hospital, Coimbatore 641032, Tamil Nadu, India; sarasbavish@gmail.com

5 Government Primary Health Center, Kalamaruthur, Kallakurichi 606202, Tamil Nadu, India; nithijoy90@gmail.com

6 Department of Industrial and Management Engineering, Institute of Digital Anti-Aging Health Care, Inje University, 197 Inje-ro, Gimhae-si 50834, Gyeongsangnam-do, Korea

* Correspondence: dkkang@inje.ac.kr

\begin{abstract}
Extensive decision-making during the vaccine preparation period is unpredictable. An account of the severity of the disease, the younger people with COVID-19 comorbidities and other chronic diseases are also at a higher risk of the COVID-19 pandemic. In this research article, the preference ranking structure for the COVID-19 vaccine is recommended for young people who have been exposed to the effects of certain chronic diseases. Multiple Criteria Decision-Making (MCDM) approach effectively handles this vague information. Furthermore, with the support of the Intuitionistic Fuzzy Soft Set (IFSS), the entries under the new extension of the Preference Ranking Organization Method for Enrichment Evaluation-II (PROMETHEE-II) is suggested for Preference Ranking Structure. The concept of intuitionistic fuzzy soft sets is parametric in nature. IFSS suggests how to exploit an intuitionistic ambiguous input from a decision-maker to make up for any shortcomings in the information provided by the decider. The weight of the inputs is calculated under the Intuitionistic Fuzzy Weighted Average (IFWA) operator, the Simply Weighted Intuitionistic Fuzzy Average (SWIFA) operator, and the Simply Intuitionistic Fuzzy Average (SIFA) operator. An Extended PROMETHEE-based ranking, outranking approach is used, and the resultant are recommended under the lexicographic order. Its sustainability and feasibility are explored for three distinct priority structures and the possibilities of the approach. To demonstrate the all-encompassing intuitionistic fuzzy PROMETHEE approach, a practical application regarding COVID-19 severity in patients is given, and then it is compared to other existing approaches to further explain its feasibility,
\end{abstract} and the sensitivity of the preference structure is examined according to the criteria.

Keywords: COVID-19 vaccine; extension of PROMETHEE-II; intuitionistic fuzzy soft set; preference structure

\section{Introduction}

The world is constantly being tested and teased by many demanding situations. The humongous pandemic COVID-19 has changed the whole world forever in uneven proportions. Commonly, coronaviruses cause cold, Severe Acute Respiratory Syndrome (SARS) and Middle East Respiratory Syndrome (MERS) in humans. The new coronavirus behind the 2019-2021 epidemic is causing respiratory illness called COVID-19. This is inflammable in our respiratory tract as an upside-down tree. In some instances, the infection can reach down into our alveoli. The impact of the coronavirus is more on the 
affected people, as well as outsiders. Due to the unstoppable spread of SARS-COV-2, India is struggling with the second wave of the epidemic. Medical researchers often say that vaccination is the only way to stop this spread. But the vaccine production pattern is very limited, and only a few among vaccines have been recommended for people. In contrast, the epidemic continues to pose a risk to hundreds of thousands of people every day, including young people, health workers, the elderly, and people with pre-existing illnesses. From these, who are those underlying health conditions that we want to care about vaccine preference? Who should be vaccinated first is a complicated question. The WHO Strategic Advisory group of experts on Immunization recommends using six stages of vaccine production [1]. For frontline members, the two levels of society segmentation are divided for vaccine allocation and chart-listed by Dooling K [2]. In that, healthcare workers, those who have high health risks, senior citizens, and essential workers especially those who provide services to people are recommended for the first level. The second level is for workers' caregivers and the final description is based on the neighbouring vaccine allocation segment, as well as the feasibility of the epidemic's size. So, healthcare staff and the aged people are at the forefront of the vaccine option. But, in recent times, young people are also in a risky situation. Mainly, the chronic diseased young people are in need of the vaccination pre-dominantly. Based on youngsters serological status, Bubar KM et al. [3] had proposed the vaccine prioritization with an informable approach to reduce the death rate and cumulative infection for adults aged 20 to 49 .

According to the vaccine related-chronology, and the series of pre-existing diseases, a diplomatic priority structure is required for young people. In particular, completing the vaccine requirement for the most vulnerable among the youth is one of most importance, and the optimization for this information is highly complex for the decider. Therefore, only IFSS has the ability to solve this complex system when exploring diverse sets. For example, a diabetic patient with lung injury is considered to have lung infection based on the severity of the disease in the intuitionistic fuzzy soft decision matrix. Furthermore, IFSS presents two-dimensional angles better than other systems. Many potential membership and nonmembership values are used to evaluate alternatives. Then, the underlying paradigm of the IFSS PROMETHEE approach was taken, and the results were analysed with the help of comparative analysis.

The remaining sections are summarized as follows: In the Section 3, some definitions of the package associated with the IFSS are recalled. In Section 4, the Extended PROMETHEE approach is standardized, and Section 5 refers to numerical examples to demonstrate the effectiveness of approved strategies. In Section 6, comparative and sensitivity analyses are presented under the. Then, the realization of the decision, conclusion, and future works are discussed in the final Section. The nomenclatures used for this research paper are given in Table 1.

Table 1. Nomenclatures.

\begin{tabular}{cc}
\hline COVID-19 & Coronavirus Disease 2019 \\
WHO & World Health Organization \\
PROMETHEE II & Preference Ranking Organization Method For Enrichment Evaluation-II \\
IFSS & Intuitionistic Fuzzy Soft Set \\
IFWA & Intuitionistic Fuzzy Weighted Average \\
SWIFA & Simply Weighted Intuitionistic Fuzzy Average \\
SIFA & Simply Weighted Intuitionistic Fuzzy Average \\
TOPSIS & Technique for Order Preference by Similarity to Ideal Solution \\
IF-VIKOR & Intuitionistic Fuzzy-VIekriterijumsko KOmpromisno Rangiranje \\
EDAS & EncephaloDuroArterioSynangiosis \\
SARS & Severe Acute Respiratory Syndrome \\
MERS & Middle East Respiratory Syndrome \\
IFV & Intuitionistic Fuzzy Value \\
\hline
\end{tabular}


Table 1. Cont.

\begin{tabular}{cc}
\hline AIFV & Aggregated Intuitionistic Fuzzy Value \\
AIFPV & Aggregated Intuitionistic Fuzzy Preference Value \\
AIR & Antigen immune Response \\
CIR & Cellular immune Response \\
COS & COVID-19 causation for each disease or Side effect \\
RPI & Remediation Period or Infection \\
MM & Malignance of Medicine \\
COE & Conservation regard environmental sustainability or \\
LA & Econamical inconvenient \\
\end{tabular}

\section{Literature Review}

Generally, decision-making is done with various conditions and certain approaches. In that, the Multi criteria Decision-Making (MCDM) approach is most suitable for stochastic problems and the alternatives are weighted with a set of parameters and alternative behaviours are screened from self-contained perspectives. Ishizaka et al. [4] discussed different forms of MCDM approaches, as well as effective methods and software for leading techniques. According to the literature point of view, set strategies are needed in the decision-making process for determining the numerous functions of decision information.

A fresh way of approach about uncertainty was specified by L. A. Zadeh[5]. In that, the uncertainty levels of particular objects are numbered with certain algebraic operations and Zadeh explained several approaches and ideas regarding the fuzzy set. In soft computing, the concept of a fuzzy set is crucial. The fundamental concept of the soft set is analyzed by Molodtsov [6], and some applications of soft set theory are presented there. In fuzzy soft set theory, theoretical approaches, logical operations, like AND, OR conditions, and Union, D'Morgans Laws are categorized by Maji et al. [7]. Atanassov's [8] intuitionistic fuzzy set is analyzed by certain properties with binary, logical, and topological operators. Then, the generalization of the intuitionistic fuzzy set is defined and summarized with an example. Maji et al. [9] proposed the intuitionistic fuzzy soft set theory which has attention, especially in decision-making.

Along with the intuitionistic fuzzy environment and an account of the TOPSIS method, Nuri et al. [10] proposed the sustainability triangle analysis approach to show the performance of the weighting method in each dimension. The intuitionistic fuzzy hybrid VIKOR method is evaluated by Zhao et al. [11]. In that, subjective and objective weights of the criteria are calculated, and the described approach is highlighted. Feng et al. [12] suggested the Enhancing PROMETHEE method and its optimization is determined by three linguistic preference structures. Intuitionistic fuzzy soft set (IFSS) based on similarity measures are also determined. The MABAC and the EDAS methods are described by Peng et al. [13], and these methods are validated with some numerical illustrations. Ibrahim M. Hezam et al. [14] suggested the prioritization structure of the COVID-19 vaccine for the frontline members with the help of the MCDM approach. In MCDM, by using the Neutrosophic TOPSIS method, the decision matrix was defuzzified on account of four main criteria and fifteen subcriteria. The elderly, essential workers, pregnant and lactating female mothers, and people at high health risk receive the vaccine dose first, followed by the most appropriate vaccine preferencers, who are patients and health workers and take precedence over other alternative vaccines.

According to the decision-maker perspectives, the discrete degree of importance to each criterion is formalized by Chen and Tan [15]. With this, the degree of accuracy for undetermined membership values, according to each criterion proposed by Hong and Choi [16]. The ordinal-based intuitionistic fuzzy subsets properties are investigated and systematized by Yager [17]. The Atanassov set of orthopairs indicate the IFS of orthopair degree of membership support.The Pythagorean set is the second form of the classic intuitionistic set, and the power of Orthopair is identified by q-rung orthopair fuzzy sets. The intuitionistic fuzzy numbers, as well as their score and accuracy functions, were introduced by Wei [18]. 
Some intuitionistic fuzzy operators are characterized by Xu [19]. Those are the Intuitionistic Fuzzy Weighted Averaging (IFWA) operator, the Intuitionistic Fuzzy Ordered Weighted Averaging (IFOWA) operator, and the Intuitionistic Fuzzy Hybrid Aggregation (IFHA) operator. Feng et al. [20] introduced membership, non-membership, ranking, accuracy, and expectation-based score functions related to lexicographic orders. Three distinct and compatible pre-order properties were also developed for the algebraic sum and scalar product operations of intuitionistic fuzzy values. In the fuzzy set theory, an intuitionistic fuzzy preference relation is transformed into an interval-valued intuitionistic fuzzy preference relation for group decision-making, which is proposed by $\mathrm{Xu}$ and Yager [21].

\subsection{Motivation for the Research}

The motivations of this research paper are as follows:

- The main goal of this investigation is to prescribe a prevalent vaccine option structure to young people against their chronic diseases and COVID-19 infection.

- $\quad$ To extend the PROMETHEE decision-making method in an IFSS environment.

- $\quad$ To use the MCDM model to overcome the difficulty situation of implementing the Extended PROMETHEE approach in an IFSS environment to achieve a clearer result in a particular way.

- $\quad$ To find the appropriate optional framework for those with chronic illness.

- Compared to other methods, unknown values are particularly demonstrated using PROMETHEE-II, and the intuitionistic fuzzy soft set approach completes decisive views on every aspect. Therefore, we plan to propose an Extended PROMETHEE method in the IFSS environment to provide the most appropriate option framework.

\subsection{Contributions of the Research}

The contributions of this research paper are as follows:

- We have introduced the MCDM approach, which includes two types of weight detection. They are based on partially known values and completely unknown values. In that, we used the weight finding equation for completely unknown values.

- Unique ranking approaches are used to determine the preference structure. Those are IFWA, SWIFA, and SIFA.

- Here, we present Wei's weight detection method for evaluating initial priority structure. (Note that the weights obtained are provided by experts using the linguistic scale.)

- Using the score and accuracy function Xu and Yager's priority structure and SWIFA operator can overcome the shortcomings of the MCDM models in obtaining the prevalence structure.

- We have proposed a SWIFA operator with lexicographic order to provide an appropriate solution with an Extended PROMETHEE method for higher performance compared to other MCDM methods.

- We have explored and evaluated the above application with various methods in the comparison analysis platform, and the sensitivity of the IFSS is determined by the sensitivity analysis.

\section{Preliminaries}

In this section, the general observation about the soft set, fuzzy soft set, L-fuzzy set, intuitionistic fuzzy set, and intuitionistic fuzzy soft set are explained, and those definitions are also stated.

A well-defined set in which each element with degree of membership is generally known as the Fuzzy set. In the ever expanding research field, the concept fuzzy set has extended with enormous branches. The origin of the fuzzy set is attributed to Lotfi A. Zadeh [5] in 1965. 


\section{Soft Set (Molodtsov) [6]:}

The soft set is a widespread mathematical tool for dealing with uncertainty or vagueness. The generalized fuzzy set is simply called soft set which satisfies binary operations and which is an easily approachable set for the decision-maker when they need to take the decision at the time of risk situations.

Definition 1. Let the universal set be $X$, and $P(Z)$ be the power set of $Z$. Let the set of all parameters be $E_{i}$, for all $i=1,2, \ldots, n$ and $Z \subseteq E_{i}$. Then, a soft set is defined by $F_{Z}$ over $Z$ which is defined by approximate function $\left(f_{z}\right)$ maps from $E_{i} \rightarrow P(Z)$, i.e., $f_{z}: E_{i} \rightarrow P(Z)$ such that $f_{z}(a)=\phi$, if $b \notin Z$. Here, a soft set is also defined by the set of all ordered pairs $F_{A}=\left(Z, F_{Z}(a)\right): a \in E_{i}$.

\section{Fuzzy Soft Set (Maji et al.) [7]:}

A soft set that has the values of its approximate function is known as a fuzzy soft set, and those binary operations are clarified under several perspectives.

Definition 2. Let the set of all fuzzy sets over $Z$ be $V(Z)$. Then, a fuzzy soft set $\bar{V}_{B}$ over $P(Z)$ is a set defined by a function representing a mapping $\tilde{V}_{B}: E \rightarrow V(Z)$ such that $\tilde{V}_{B}(z)=\phi: z \in B$, where $\phi$ is the fuzzy empty set, $\bar{V}_{B}$ is called approximate function of the fuzzy soft set $\tilde{V}_{B}$, and the value of $\tilde{V}_{B}(z)$ is a set called the z-element.

Intuitionistic Fuzzy Set (Atanassov) [8]:

If a fuzzy soft set has membership and non-membership grades, then it is stated as Intuitionistic Fuzzy soft.

Definition 3. Let $Z$ be a non-empty set which is finite, and those values are crisp. An intuitionistic fuzzy subset $\bar{B}$ of $X$ is defined by $\tilde{B}=\left\{z, m_{B}(z), n_{B}(z): z \in Z\right\}$, where the functions $m_{B}(z)$ and $n_{B}(Z)$ are defined from $X$ to $[0,1]$ with the condition $0 \leq m_{B}(z)+N_{B}(z) \leq 1$ for all $z \in Z$. Here, $m_{B}(z)$ and $n_{B}(z)$ are membership and non-membership values of the function, and the hesitancy value is $\pi_{B}(z)=1-m_{B}(z)-n_{B}(z)$, which is known as degree of uncertainty of the element $z \in Z$ to the intuitionistic fuzzy set $\bar{B}$.

- $\quad$ Every fuzzy set can be viewed as an intuitionistic fuzzy set. An L-fuzzy set $C$ on a set $X$ is a function $C: Z \rightarrow L$. Thus, fuzzy sets are equal as functions, $\left(L_{f}^{*}, \leq_{L_{f}^{*}}\right)$, where $L_{f}^{*}=(m, n) \in[0,1]^{2}|m+n| \leq 1$, and every ordered pair $(m, n) \in L_{f}^{*}$ is denoted as intuitionistic fuzzy value. The corresponding lattice order $\leq_{L_{f}^{*}}$ is defined as $\left(z_{1}, z_{2}\right)$ $\leq_{L_{f}^{*}}\left(y_{1}, y_{2}\right) \leftrightarrow\left(z_{1} \leq y_{1}\right) \wedge\left(z_{2} \geq y_{2}\right)$.

Intuitionistic Fuzzy Soft Set (Maji et al.) [9]:

An intuitionistic fuzzy set has the values of its approximate function which is known as intuitionistic fuzzy soft set.

Definition 4. Let $\tilde{Z}(V)$ be a set of all intuitionistic fuzzy sets over $V$. Then, an intuitionistic fuzzy soft set $\Gamma B$ over $\tilde{Z}(V)$ is a set defined by a function such that $v_{B}: E_{i} \rightarrow \tilde{Z}(V)$ such that $v_{B}(z)=$ $\tilde{\phi}$, if $x \notin B$, where $\tilde{\phi}$ is the intuitionistic fuzzy empty set called $x$-element of $\Gamma B$ for all $x \in E_{i}$. So, it is defined by: $v_{B}(z)=\left\{\left(v, m_{v_{B(z)}}(v), n_{v_{B(z)}}(v): v \in V\right\}, \forall x \in E_{i}\right.$.

\section{Extended PROMETHEE-II in IFSS}

In this section, the decision matrix notations and descriptions are briefly explained. In the first subsection, the definitions and derivations of the aggregation and ranking methodology are explained. Wei's maximizing deviation method is shown for finding the weight values of each criterion. In the second subsection, PROMETHEE-related criteria and outranking procedures are proposed in the IFSS environment. 
Let us Consider $v=(\omega, B)$ be an IFSS over $\mathrm{D}$ and $c_{v} \in B$. For every pair of alternatives $d_{w}, d_{l} \in D$ and each $c_{v} \in B$, and we describe the respective notations as follows.

- $m_{w l}(v)=\max \left(\left(m_{w v}-m_{l v}\right), 0\right)$ and

- $n_{w l}(v)=\max \left(\left(n_{w v}-n_{w v}\right), 0\right)$.

Here, $u, v$, and $w$ represent $i$ th, $j$ th, and $k$ th values in the corresponding decision matrix, respectively.

- With the above, the Extended PROMETHEE method is introduced by Feng et al. [12] in the IFSS environment and is described as follows. Consider $D=d_{1}, d_{2}, \ldots ., d_{n}$, the set of alternatives and $C=c_{1}, c_{2}, \ldots ., c_{n}$, the set of criteria. Let $y=\left(y_{1}, y_{2}, \ldots ., y_{n}\right)^{T}$ be the weight vector with $y_{u} \in[0,1],(u=1,2, \ldots, n)$ and $\sum_{u=1}^{n} y_{u}=1$. The decision matrix is denoted by $\mathrm{M}=\left(b_{u v}\right)_{m \times n}$, and, converting the cost criteria to beneficial criteria, the decision matrix is changed as $S=\left(s_{u v}\right)_{m \times n}$.

\subsection{Aggregation Operators for IFSS}

$\mathrm{Xu}$ [19] defined some basic logical operational laws of information measures of the intuitionistic fuzzy soft set environment. The aggregation of IFV is stated as follows.

Theorem 1. Let $\delta_{u}=\left(m_{\delta_{u}}, n_{\delta_{u}}\right) \in L_{f}^{*}(u=1,2, \ldots, n)$. Then, we have $\Psi_{y}\left(\delta_{1}, \delta_{2}, \delta_{3}, \ldots \ldots, \delta_{n}\right)=$ $\left(1-\prod_{u=1}^{n}\left(1-m_{\delta_{u}}\right)^{y_{u}}, \prod_{u=1}^{n}\left(n_{\delta_{u}}\right)^{y_{u}}\right)$, where $y=\left(y_{1}, y_{2}, \ldots . ., y_{n}\right)^{T}$ is the weight vector.

\section{Maximizing deviation method:}

Let us briefly recall the maximum deviation method for determining the weight vector $y=\left(y_{1}, y_{2}, \ldots, y_{n}\right)^{T}$, and we need to choose a weight vector $y$ to increase Wei's basic idea. In general, the two components are normalized when the hamming distance is found. Based on the hamming distance, the maximum deviation method is abbreviated by Wei, which has two types of alternatives. The type- 1 Wei equation is related to somewhat known weight vectors, and the type-2 Wei equation is related to completely unknown weight vectors.

The total weight deviation value between all the substitutes and properties is derived. Based on two types, we outline the equation of type- 2 Wei and make some necessary changes as follows. For the single objective programming model, the weight vector of the equation of type-2 Wei is as follows.

$$
w_{v}=\frac{\sum_{u=1}^{m} \sum_{w=1}^{m}\left(\left|m_{u v}-m_{w v}\right|+\left|n_{u v}-n_{w v}\right|\right.}{\sum_{v=1}^{n} \sum_{u=1}^{m} \sum_{w=1}^{m}\left|m_{u v}-m_{w v}\right|+\left|n_{u v}-n_{w v}\right|}, \text { for }, u=1,2, \ldots, n .
$$

(i) IFWA Operator $(\mathrm{Xu})$ [19]: By the use of L-fuzzy set, the intuitionistic fuzzy weighted average is defined. It has been used in a wide range of applications.

Definition 5. Intuitionistic fuzzy weighted averaging (IFWA) operator of dimension $n$ is a mapping $\Psi_{y}:\left(L_{f}^{*}\right)^{n} \rightarrow L_{f}^{*}$ given by: $\Psi_{y}\left(\delta_{1}, \delta_{2}, \delta_{3}, \ldots . ., \delta_{n}\right)=y_{1} \delta_{1} \oplus y_{2} \delta_{2} \oplus \ldots \ldots . y_{n} \delta_{n} \oplus$, where $W$ $=\left(y_{1}, y_{2}, \ldots, y_{n}\right)^{T}$ is the weight vector such that $y_{i} \in[0,1](u=1,2, \ldots, n)$ and $\sum_{u=1}^{n} y_{u}=1$. Especially, if $y=\tilde{y}=(1 / n, 1 / n, \ldots ., 1 / n)^{T}$, then, $\sum_{y}$ is simply written as $\psi$ which is known as Intuitionistic Fuzzy Average Operator, i.e., $\Psi_{y}\left(\delta_{1}, \delta_{2}, \delta_{3}, \ldots, \delta_{n}\right)=1 / n\left(\delta_{1} \oplus \delta_{1} \oplus \ldots . . \delta_{1} \oplus\right)$.

(ii) SWIFA Operator ( $\mathrm{Xu}$ and Yager) [21]:

We use the SWIFA operator while determining the preference in lexicographic order. Here, $\delta_{i}$ is a positive real number for all $i$.

Definition 6. Let $\delta_{u}=\left(m_{\delta_{u}}, n_{\delta_{u}}\right)(u=1,2, \ldots, n)$ be IFVs in $L_{f}^{*}$. The simply weighted intuitionistic fuzzy averaging(SWIFA) operator of dimension $n$ is a mapping $\phi_{y}^{t}:\left(L_{f}^{*}\right)^{n} \rightarrow L_{f}^{*}$ given by: $\phi_{y}^{t}\left(\delta_{1}, \delta_{2}, \delta_{3}, \ldots . ., \delta_{n}\right)=\left(\sum_{u=1}^{n} y_{u} m_{\delta_{u}}, \sum_{u=1}^{n} y_{u} n_{\delta_{u}}\right)$, where $y=\left(y_{1}, y_{2}, \ldots ., y_{n}\right)^{T}$ is the weight vector such that $y_{u} \in[0,1](u=1,2, \ldots, n)$ and $\sum_{u=1}^{n} y_{u}=1$. 
(iii) SIFA Operator ( $\mathrm{Xu}$ and Yager) [21]:

If $y=(1 / n, 1 / n, \ldots ., 1 / n)^{T}$, then $\Phi^{t}$ is called a simple intuitionistic fuzzy averaging operator, and it is defined by: $\Phi^{S}\left(\delta_{1}, \delta_{2}, \ldots ., \delta_{n}\right)=\left(1 / n \sum_{u=1}^{n} m_{\delta_{u}}, 1 / n \sum_{u=1}^{n} n_{\delta_{u}}\right)$.

\subsection{Ranking Methodology}

Chen and Tan [15], as well as Hong and Choi [16], have validated the IFV's score and accuracy function. From the well-defined set, they have derived an ordered pair of membership and non-membership values, which must be an IFV. Then, in an order of membership values and score values, preference structure was established owing to the outstanding work of Xu and Yager [17]. Then, based on their intellectual work, Feng et al. [20] introduced the various forms of lexicographic orders, which are identified along with different perspectives, and their interpretation (Definition 7) and diagrammatical representation (Figure 1) are discussed below.

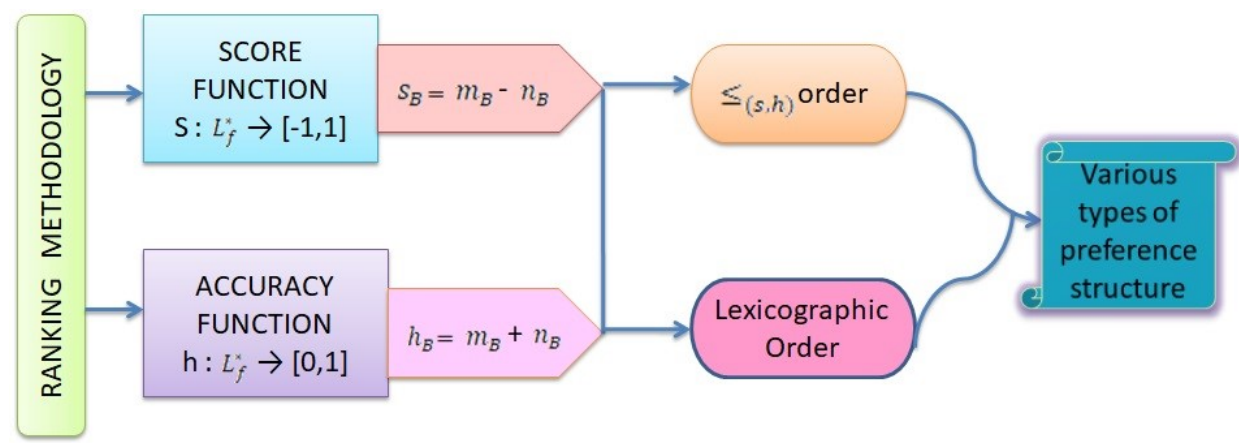

Figure 1. The ranking perspectives.

Definition 7. Let $B=\left(m_{B}, n_{B}\right)$ and $C=\left(m_{C}, n_{C}\right)$ be IFVs in $L_{f}^{*}$. The binary relation $\leq(s, m)$ on $L_{f}^{*}$ is given by:

- $B \leq_{(s, h)} C \Leftrightarrow\left(s_{B}<s_{C}\right) \cup\left(s_{B}=s_{C} \cap h_{B} \leq h_{C}\right)$.

- $B \leq_{(s, m)} C \Leftrightarrow\left(s_{B}<s_{C}\right) \cup\left(\left(s_{B}=s_{C}\right) \cap\left(m_{B} \leq m_{C}\right)\right)$.

- $B \leq_{(s, n)} C \Leftrightarrow\left(s_{B}<s_{C}\right) \cup\left(\left(s_{B}=s_{C}\right) \cap\left(n_{B} \geq n_{C}\right)\right)$.

- $B \leq_{(m, n)} C \Leftrightarrow\left(m_{B}<m_{C}\right) \cup\left(\left(m_{B}=m_{C}\right) \cap\left(n_{B} \geq n_{C}\right)\right)$.

- $B \leq_{(n, m)} C \Leftrightarrow\left(n_{B}<n_{C}\right) \cup\left(\left(n_{B}=n_{C}\right) \cap\left(m_{B} \geq m_{C}\right)\right)$.

Proposoition 1. Let $B=\left(m_{B}, n_{B}\right)$ and $C=\left(m_{C}, n_{C}\right)$ be IFVsin $L_{f}^{*}$. Then, $B \leq_{(s, h)} C \Leftrightarrow B \leq_{(s, m)} C$.

\subsection{The Criterion-Based PROMETHEE}

The PROMETHEE method provided a well-established criterion formation, and it is based on pairwise comparisons. In that, an outranking method is proposed here by IFSS which is named Extended PROMETHEE. The preference structure has desirable binary relations and satisfies the operational laws according to binary conditions.

Definition 8. A function $F: \Re \rightarrow[0,1]$ is called an evaluation criterion if it satisfies the following conditions: $F(0)=0 ; F(-a)=F(a) ; \forall a, b \in[0,+\infty), a<b \Longrightarrow F(a) \leq F(b)$.

From an evaluation criterion, the functions are even when passing through the origin and non-decreasing in $[0,+\infty)$. The most commonly used evaluation criteria are usual, linear, and level criteria.

Definition 9. Let $F: \Re \rightarrow[0,1]$ be an evaluation criterion and $\Psi=(\tilde{v}, B)$ be an IFSS over $D$. Let $y=\left(y_{1}, y_{2}, \ldots, y_{n}\right)^{T}$ be the weight vector with $y_{u} \in[0,1](u=1,2, \ldots, n)$ and $\sum_{u=1}^{n} w_{u}=1$. The matrix $P^{\tilde{v}}=\frac{1}{2}\left(P_{M}^{\tilde{v}}+P_{N}^{\tilde{v}}\right)$ is called the aggregated intuitionistic fuzzy preference matrix of the IFSS 
$\tilde{v}$. Here, $P_{M}^{\tilde{v}}=\sum_{u=1}^{n} w_{v} P_{M_{v}}^{\tilde{v}} P_{N}^{\tilde{v}}=\sum_{u=1}^{n} y_{v} P_{N_{v}}^{\tilde{v}}$, where $P_{M}^{\tilde{v}}$ and $P_{N}^{\tilde{v}}$ are aggregated intuitionistic fuzzy membership and non-membership preference matrices of the IFSS $\tilde{v}$.

Definition 10. For every pair of alternatives $d_{w}, d_{l} \in U$, the preference degree of $d_{w}$ over $d_{l}$, denoted by $P_{w l}^{v}$, is called the uni-criterion preference degree of $d_{w}$ over $d_{l}$. It is defined as $P_{w l}=$ $\sum_{v=1}^{n} w_{v} P_{w l}^{(v)}$.

\subsection{Outranking Method}

The positive flow and the negative flow of superiority and indifference relations on $D$ are determined with the required results, and the theoretical explanation about positive flow and negative flow is similar to the net flow. So, it is left to the reader. The net flow of superiority and indifference relation on $D$ can be understood from the following results.

Proposoition 2. Let $\tilde{v}=(\omega, B)$ be an IFSS over $D$ and $c_{j} \in B$. The intuitionistic fuzzy membership deviation matrix $M_{j}=\left(m_{k l}(j)\right)_{\times(m m)}$ satisfies the following properties:

1. $m_{w l}(v)>0 \rightarrow m_{l v}(j)=0$;

2. $m_{w l}(v)=0 \rightarrow m_{l v}(j) \geq 0$.

Proof. Let us suppose that $m_{w l}(v)>0$. Then, we have $m_{w v}-m_{l v}>0$ since $m_{w l}(v)=$ $\max \left(m_{w v}-m_{l v}\right), 0$. Meanwhile, we also have $m_{l v}-m_{w v}<0$. It follows that $m_{l w}(v)=0$, since $m_{l w}(v)=\max \left(m_{l w}-m_{w v}\right), 0$. Next, suppose that $m_{w l}(v)=0$, and the following two cases should be considered:

1. If $m_{w v}=m_{l v}$, then we have $m_{l w}(v)=0$.

2. If $m_{w v}<m_{l v}$, then we have $m_{l w}(v)>0$.

From these two cases, we can deduce that $m l w(v) \geq 0$, which concludes the proof.

Proposoition 3. Let $\tilde{v}=(\omega, B)$ be an IFSS over $D$ and $c_{v} \in B$. The intuitionistic fuzzy membership deviation matrix $N_{v}=\left(n_{w l}(v)\right)_{\times(m m)}$ satisfies the following properties:

1. $\quad n_{\text {wwl }}(v)>0 \rightarrow n_{l w}(v)=0$;

2. $n_{w l}(v)=0 \rightarrow n_{l w}(v) \geq 0$.

Proof. The proof is similar to that of Proposition 2 and, thus, is omitted.

Theorem 2. Let F: $\Re \rightarrow[0,1]$ be an evaluation criterion and $\tilde{v}=(\omega, B)$ be an IFSS over $U$. Then, we have the following: $>^{\tilde{v}}$ is a superiority relation on $U$; ${ }^{\tilde{v}}$ is an indifference relation on $U$; $(D,>\tilde{v}, \tilde{v})$ is a preference structure.

Proof. To prove that $>^{\tilde{v}}$ is a superiority relation on $\mathrm{U}$, we need to satisfy the defined statement, "A preference relation ' $>$ ' on B is called a superiority relation if it is asymmetric and transitive". First, we assume $>^{\tilde{v}}$ is not asymmetric. Then, there exist $d_{w}$ and $d_{l}$ in D such that both $d_{w}>^{\tilde{v}} d_{l}$ and $d_{l}>^{\tilde{v}} d_{w}$ hold. We know that net flow superiority relation on $\mathrm{D}$ is defined as $d_{w}>^{\tilde{v}} d_{l} \Longleftrightarrow \psi^{\tilde{v}}\left(d_{w}\right)>\psi^{\tilde{v}}\left(d_{l}\right)$. But, if we take $\psi^{\tilde{v}}\left(d_{w}\right)>\psi^{\tilde{v}}\left(d_{l}\right)$ and $\psi^{\tilde{v}}\left(d_{l}\right)$ $>\psi^{\tilde{v}}\left(d_{w}\right)$, it contradicts our assumption. Hence, $>^{\tilde{v}}$ is asymmetric.

Next, we need to show that $>^{\tilde{v}}$ is transitive. Suppose that $d_{w}>^{\tilde{v}} d_{l}$ and $d_{l}>^{\tilde{v}} d_{p}$ hold for $d_{w}, d_{l}, d_{p} \in D$. From the hypothesis, net flow superiority relation has $d_{w}>\tilde{v} d_{l}$ $\Longleftrightarrow \psi^{\tilde{v}}\left(d_{w}\right)>\psi^{\tilde{v}}\left(d_{l}\right)>$. We have $\Psi \tilde{v}\left(d_{w}\right)>\Psi \tilde{v}\left(d_{l}\right)$ and $\Psi \tilde{v}\left(d_{l}\right)>\Psi \tilde{v}\left(d_{p}\right)$, which implies that $d_{w}>^{\tilde{v}}>d_{p}$. Hence, $>^{\tilde{v}}$ is transitive. Thus, $>^{\tilde{v}}$ is a superiority relation on $D$.

Similarly, if we say $\tilde{v}$ is an indifference relation on $D$, we need to verify two predefined statements which are (1). 'An indifference relation on $B$ is called an indifference relation if it is reflexive, symmetric, and transitive', and (2). 'The net flow indifference relation on $D$ is defined as $d_{w} \tilde{v}^{\tilde{v}} d_{l} \Longleftrightarrow \psi^{\tilde{v}}\left(d_{w}\right) \psi^{\tilde{v}}\left(d_{l}\right)^{\prime}$.

Here, $\psi^{\tilde{v}}\left(d_{w}\right)=\psi^{\tilde{Y}}\left(d_{w}\right)$. With this, the reflexivity condition is satisfied. From statement (2), we summarize that the transformation is symmetric. Further, it follows the 
transitivity condition elaborated in case (1) and satisfies statement (2). Thus, the transitive relation is proved with it. Hence, $\tilde{v}$ is a indifference relation on $D$.

Generally, superiority and indifference relations demand the conditions jointly complete and jointly transitive for occurred the preference structure $(D, \tilde{v}, \tilde{v})$. The required relation follows the jointly complete and jointly transitive conditions. Thus, we conclude with the preference structure.

From the above, we can derive PROMETHEE's outranking approach in a prescribed manner. Let $\tilde{v}=(\omega, B)$ be an IFSS over $D$ and $c_{v} \in B$. For simplification, the following notations about the level criteria of membership function $M_{v}^{\tilde{v}^{\min }}$ are derived as follows.

$$
\begin{gathered}
\qquad M_{v}^{\tilde{v}^{\min }}=\min _{1 \leq w, l \leq m} m_{w l}(v) \mid m_{w l}(v)>0, \\
\qquad M_{v}^{\tilde{v}^{\max }}=\max _{1 \leq w, l \leq m} m_{w l}(v) \text { and } \\
\text { the positive ideal solution, } M_{v}^{\tilde{v}}=\frac{1}{c_{m}^{2}} \sum_{w=1}^{m} \sum_{l=1}^{m} m_{w l}(v) .
\end{gathered}
$$

The positive flow, $p_{v}^{+}$, and negative flow, $q_{v}^{+}$, of membership values are expressed as

$$
\begin{gathered}
p_{v}^{+}=\max M_{v}^{\tilde{v}^{\min }}, \frac{1}{2} M_{v}^{\tilde{v}} \text { and } \\
q_{v}^{+}=\min M_{v}^{\tilde{v}^{\max }}, \frac{3}{2} M_{v}^{\tilde{v}} .
\end{gathered}
$$

In the same way, we can determine $p_{v}^{-}$and $q_{v}^{-}$for non-membership values $N_{v}^{\tilde{v}}$. The level criteria of the non-membership function are derived as follows:

$$
\begin{gathered}
\qquad N_{v}^{\tilde{v}^{\min }}=\min _{1 \leq w, l \leq m} m_{w l}(v) \mid m_{w l}(v)>0, \\
N_{v}^{\tilde{v}^{\max }}=\max _{1 \leq w, l \leq m} m_{w w l}(v) \text { and } \\
\text { the negative ideal solution, } N_{v}^{\tilde{v}}=\frac{1}{c_{m}^{2}} \sum_{w=1}^{m} \sum_{l=1}^{m} m_{w l}(v) .
\end{gathered}
$$

The positive flow, $p_{v}^{-}$, and negative flow, $q_{v}^{-}$, of membership values are described as

$$
\begin{gathered}
p_{v}^{+}=\max N_{v}^{\tilde{v}^{\min }}, \frac{1}{2} N_{v}^{\tilde{v}} \text { and } \\
q_{v}^{+}=\min N_{v}^{\tilde{v}^{\max }}, \frac{3}{2} N_{v}^{\tilde{v}} .
\end{gathered}
$$


We now provide an algorithm (Algorithm 1) for the extended PROMETHEE-II in the IFFSS. Figure 2 gives an overview of the algorithm for this Extended PROMETHEE method.

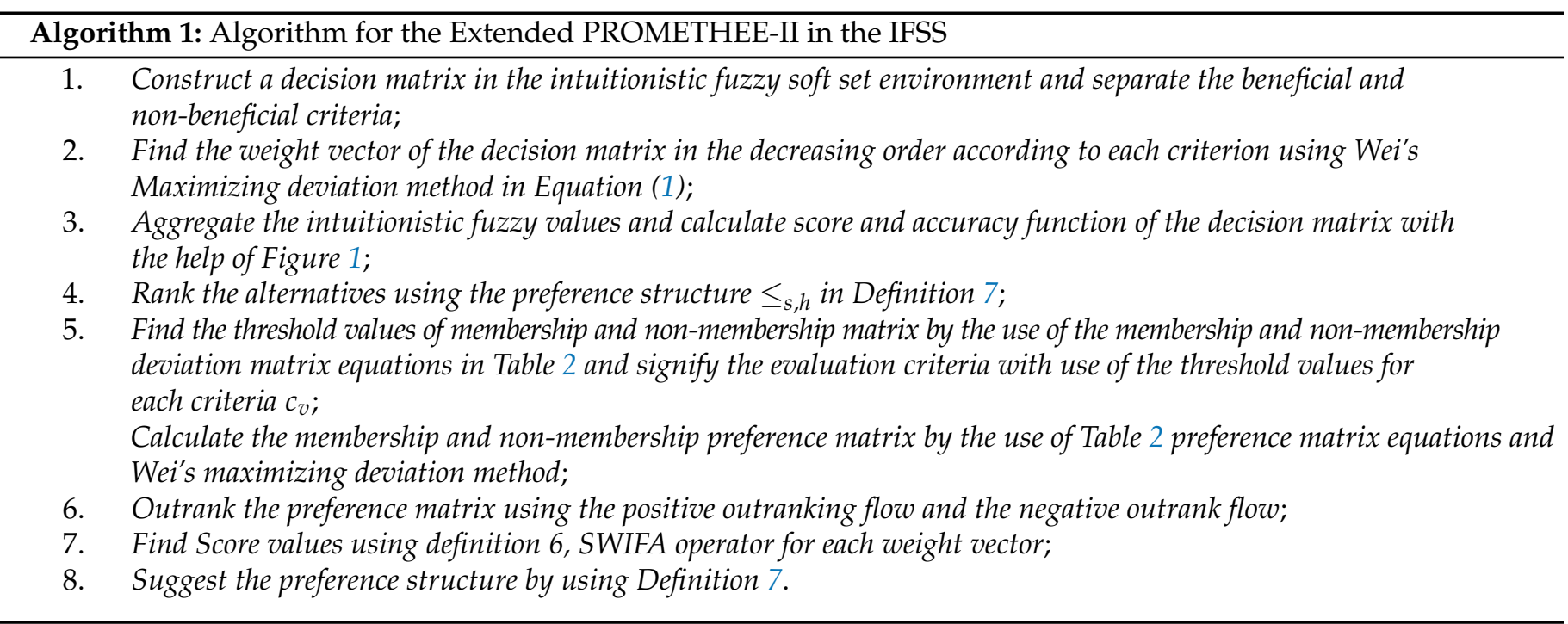

Table 2. Defined formulae of deviation and preference matrices

\begin{tabular}{ccc}
\hline Fuzzy Values & Deviation Matrix & Preference Matrix \\
\hline Membership & $M_{v}^{\tilde{v}}=\left(m_{w l}(v)\right)_{m \times m}$ & $P_{M_{v}^{\tilde{v}}}=\left(F\left(m_{w l}(v)\right)\right)_{m \times m}$ \\
\hline Non-membership & $N_{v}^{\tilde{v}}=\left(n_{w l}(v)\right)_{m \times m}$ & $P_{N_{v}^{\tilde{v}}}=\left(F\left(m_{w l}(v)\right)\right)_{m \times m}$ \\
\hline
\end{tabular}

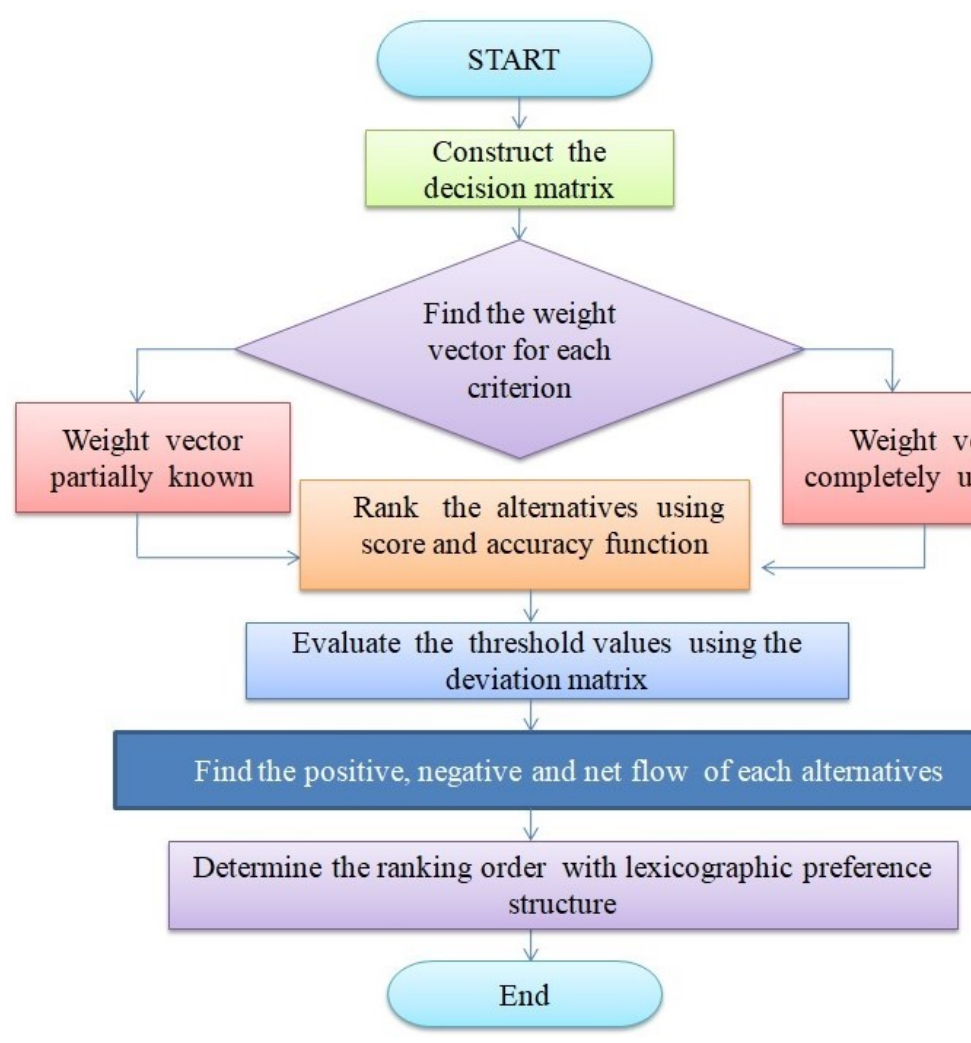

Figure 2. Overview of the algorithm for the Extended PROMETHEE method. 


\subsection{Decider Perspectives about Criteria}

In this study, we aggregate the information regarding COVID-19 inflammations from clinical experts. What are those underlying health conditions that we need to care about for vaccine preference pre-dominantly? The clinical experts are not unanimous and have fluctuations for predicting the preference in the vaccination period. Because, while the decider compares to the CORONA positive people with COVID-19 comorbidities that lead to the sophisticated decision, it does not depend on the human age. So, the line up for vaccine preference is investigated for young people in Extended PROMETHEE with beneficial and non-beneficial criteria. Youngsters are majorly in infectious situations, and these disease risk factors are also the same for COVID-19 comorbidities and chronic diseases.

According to the clinical experts' perspectives, the COVID-19 patients' comorbidities are taken as alternatives, and their health responses with regard to the chronic diseases are valued as criteria. Mainly, vaccination is suggestible for people with regard to their safety measurements. So, the decider considers the criterion in the respective manner: (1.) Health condition of the CORONA positive people and (2.) socio-environment of the CORONA positive people [15-35].

(1) Health Condition of diseased people: In an account of people's health, the clinical experts mainly consider the immune response in cells and antigen immune response and malignancy of vaccine.

(2) Socio-environment of the diseased people: Environmental acceptability of the patient is recognized in the respective point of view that are causation, remediation, and lesser agitation.

Alternatives to the scale are recommended based on consistency. When vaccinating young people with chronic illness, we must pay close attention to certain criteria. Furthermore, it can be seen from the following explanations that the processes of criteria are consistent with the recommendation for alternative vaccine structure.

\section{- Antigen immune Response (AIR) $\left(c_{1}\right)$}

Antigen immune Response is denoted as AIR. Usually, people with chronic diseases are in the most vulnerable situation against corona. In particular, antigen immune response is low for chronic diseased youngsters. Therefore, it becomes necessary to take antigen immune response to discuss the primary structure of those affected by chronic diseases in the criteria.

\section{- Cellular immune Response (CIR) $\left(c_{2}\right)$}

Cellular immune response is named as CIR. Chronic diseases are multifactorial conditions that are considered serious public health problems, accounting for sixty percent of deaths worldwide. The immune system plays an important role in many processes involving chronic diseases. Vaccination against cellular immunity, which includes cancer, metabolic syndrome, heart disease, and others, helps to counteract the underlying patterns of these diseases.

\section{- COVID-19 causation for each disease or Side effect (COS) $\left(c_{3}\right)$}

Here, COS is denoted as COVID-19 causation for each disease or side effect. Factors against coronavirus are clearly explained here. The first prognostic factors are the factors that make the condition more vulnerable, especially if it is affected by a previous illness that increases its dosage. Active factors contribute to the development (or recovery) of the disease, e.g., economic status, immediate exposure to the disease agent, or factors associated with disease onset. Factors that exacerbate pre-existing disease may be, e.g., malnutrition, recurrent manifestations. Risk factors are conditions, qualities, or characteristics, the presence of which increases a person's chances of being affected, developing or worsening by the disease process. The risk factor is not necessarily the cause of the disease, but the person exposed to the factor will increase the probability of getting the disease easily. 


\section{- Remediation Period or Infection (RPI) $\left(c_{4}\right)$}

When taking the coronavirus vaccine, the interval between solutions for chronic patients varies from generation to generation. Furthermore, chemical changes in the body of some people create unhealthy physical ailments, in which case the vaccine they take targets the immune response and creates an environment conducive to infection. Therefore, the criteria for this are briefly referred to here as RPI.

\section{- Malignancy of vaccine (MM) $\left(c_{5}\right)$}

The dosage of the vaccine for adolescents and the duration of vaccination for chronically ill adolescents are denoted as MM.

\section{- Conservation regard environmental sustainability or Economical inconvenient(COE) $\left(c_{6}\right)$}

The economic crisis has significantly affected patients and health services. Chronic patients are more susceptible to coronavirus infection. The purpose of this criterion is to examine how patients with selective chronic conditions are affected by the current economic climate. This is called COE in the criteria section.

- Lesser agitation (LA) $\left(c_{7}\right)$

Because of the high level of exposure to COVID-19, people with chronic illness may experience some degree of anxiety and depression within themselves. Proper vaccination can reduce stress for them. Therefore, these are taken as LA on the criterion scale.

\section{Numerical Exemplification}

In this section, the preference structure for the vaccine allocation is numerically illustrated. Chronic diseased people with young age are in need of vaccine. According to the COVID-19 patient's comorbidities and the chronically diseased patients, COVID-19 comorbidities clinical experts gave some suggestion. On an account of that, the decision information is formalized by the decider on the linguistic scale in Table 3.

Table 3. Linguistic scale for rating the alternatives.

\begin{tabular}{cc}
\hline Linguistic Variable & Values in the Fuzzy Scale \\
\hline Very high & 0.2 \\
High & 0.3 \\
Fairly high & 0.4 \\
Fairly low & 0.5 \\
Low & 0.6 \\
Very Low & 0.7 \\
\hline
\end{tabular}

Step 1: Single objective method is used which follows the clinical experts case study [15-35] in the appendix section, and, at the decision matrix, the respective position of alternatives and criteria are scaled as follows. These scaling specifies the intuitionistic fuzzy values and satisfies the binary and logical operations under intuitionistic fuzzy soft set environment. Therefore, diseases that can cause particularly severe damage in chronic diseases are considered as alternatives. People with COVID-19 also experience symptoms of chronic illness. That is, the people with chronic diseases and COVID-19 comorbodities are nearly same. The most severe diseases of COVID-19 comorbidities and chronic diseases are Alzheimer, blood pressure, lungs injury, heart disease, obesity, kidney damage, and diabetes are taken as alternatives and denoted as $D_{1}, D_{2}, D_{3}, D_{4}, D_{5}, D_{6}$, and $D_{7}$, respectively. Then, the criteria for the above diseases are defined according to the recommendation of medical experts, and this is clearly explained in Appendix A.

The diagrammatical representation of alternatives with respect to criteria is shown in Figure 3, and the decision information is illustrated in Table 4. 


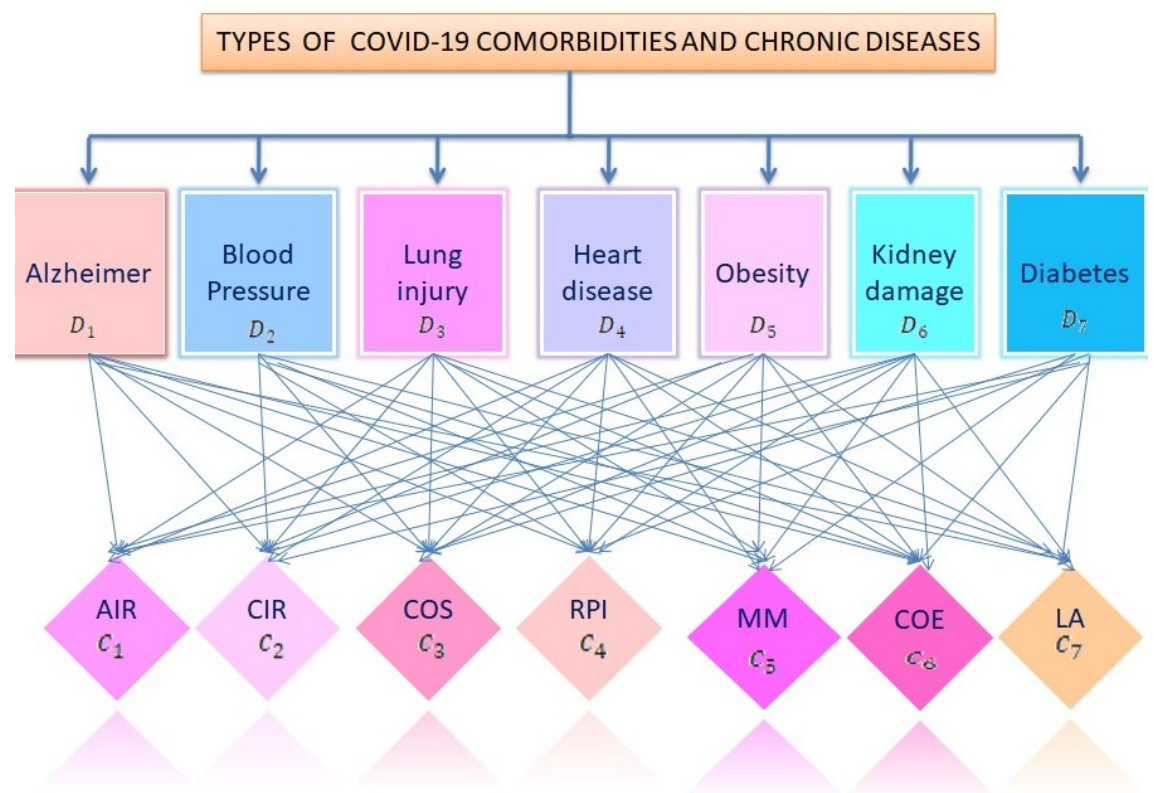

Figure 3. Graphical representation of the fuzzified intuitionistic soft set environment.

Table 4. Decision information in the intuitionistic fuzzy soft set environment.

\begin{tabular}{cccccccc}
\hline $\mathbf{X}$ & $\boldsymbol{c}_{\mathbf{1}}$ & $\boldsymbol{c}_{\mathbf{2}}$ & $\boldsymbol{c}_{\mathbf{3}}$ & $\boldsymbol{c}_{\boldsymbol{4}}$ & $\boldsymbol{c}_{\mathbf{5}}$ & $\boldsymbol{c}_{\boldsymbol{6}}$ & $\boldsymbol{c}_{\mathbf{7}}$ \\
\hline$D_{1}$ & $(0.6,0.3)$ & $(0.6,0.3)$ & $(0.4,0.5)$ & $(0.2,0.3)$ & $(0.7,0.2)$ & $(0.3,0.4)$ & $(0.6,0.4)$ \\
$D_{2}$ & $(0.5,0.4)$ & $(0.5,0.2)$ & $(0.2,0.4)$ & $(0.4,0.5)$ & $(0.6,0.3)$ & $(0.5,0.4)$ & $(0.5,0.3)$ \\
$D_{3}$ & $(0.4,0.3)$ & $(0.3,0.6)$ & $(0.2,0.3)$ & $(0.2,0.4)$ & $(0.4,0.5)$ & $(0.2,0.5)$ & $(0.3,0.6)$ \\
$D_{4}$ & $(0.3,0.2)$ & $(0.3,0.5)$ & $(0.2,0.4)$ & $(0.4,0.5)$ & $(0.3,0.6)$ & $(0.4,0.5)$ & $(0.2,0.4)$ \\
$D_{5}$ & $(0.7,0.2)$ & $(0.6,0.4)$ & $(0.3,0.6)$ & $(0.2,0.4)$ & $(0.5,0.4)$ & $(0.4,0.3)$ & $(0.6,0.2)$ \\
$D_{6}$ & $(0.3,0.5)$ & $(0.4,0.5)$ & $(0.2,0.3)$ & $(0.4,0.5)$ & $(0.4,0.6)$ & $(0.3,0.4)$ & $(0.4,0.3)$ \\
$D_{7}$ & $(0.6,0.4)$ & $(0.4,0.2)$ & $(0.3,0.5)$ & $(0.2,0.4)$ & $(0.6,0.3)$ & $(0.4,0.3)$ & $(0.5,0.3)$ \\
\hline
\end{tabular}

Step 2: By the use of maximizing deviation method, the weight of each of the criteria is calculated. The obtained weight vector is $\mathrm{y}=(0.1561,0.1729,0.1104,0.1152,0.1765$, $0.1056,0.1633)^{T}$ and $\sum_{u=1}^{n} y_{u}=1$. See Figure 4 .

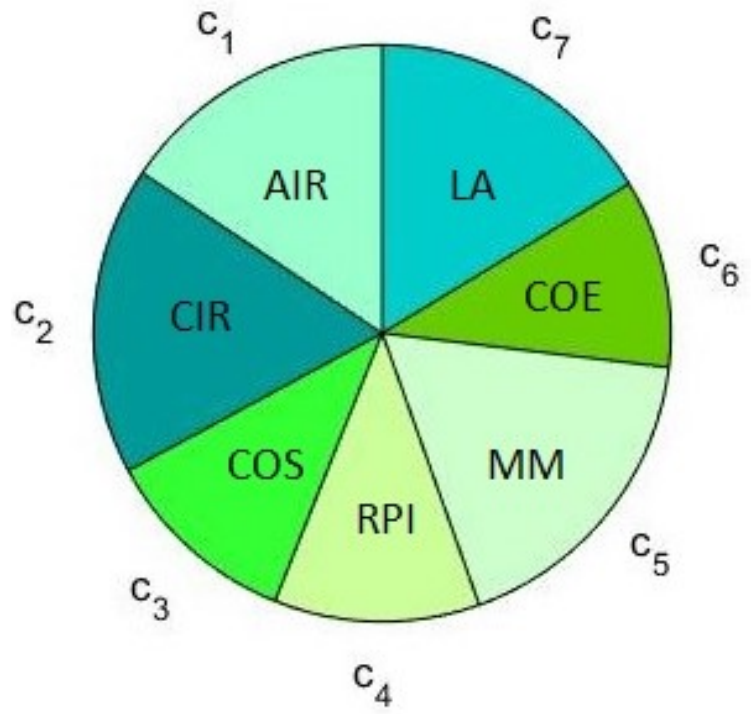

Figure 4. The weight of each criterion. 
Step 3: Intuitionistic fuzzy values are aggregated wisely. The score and accuracy function of the intuitionistic fuzzy values are evaluated in Table 5.

Table 5. AIFPVs and related measures obtained by Algorithm.

\begin{tabular}{cccc}
\hline $\mathbf{X}$ & AIFPVs & $s\left(G_{\tilde{v}}\left(\boldsymbol{B}_{\boldsymbol{i}}\right)\right)$ & $\boldsymbol{h}\left(\boldsymbol{G}_{\tilde{v}}\left(\boldsymbol{B}_{\boldsymbol{i}}\right)\right)$ \\
\hline$D_{1}$ & $(0.5136,0.3305)$ & 0.1831 & 0.8441 \\
$D_{2}$ & $(0.4685,0.3444)$ & 0.1241 & 0.1829 \\
$D_{3}$ & $(0.2908,0.4408)$ & -0.1500 & 0.7316 \\
$D_{4}$ & $(0.3042,0.4223)$ & -0.1181 & 0.7265 \\
$D_{5}$ & $(0.4978,0.3336)$ & 0.1642 & 0.8314 \\
$D_{6}$ & $(0.3322,0.4295)$ & -0.0973 & 0.7617 \\
$D_{7}$ & $(0.4764,0.3305)$ & 0.1459 & 0.8070 \\
\hline
\end{tabular}

Step 4: The alternatives are ranked, on the basis of the order $\leq_{(s, h)}$. The ranking of AIFPVs is $D_{1}>D_{5}>D_{7}>D_{2}>D_{6}>D_{4}>D_{3}$, and the rankings are graphically illustrated in Figure 4.

Step 5: Using the membership deviation matrix and the non-membership deviation matrix for each of the criteria, $c_{v}$, the thresholds of level criteria are calculated, using Table 2, and are constructed as follows.

$$
\begin{aligned}
& F_{m_{1}}(a)=\left\{\begin{array}{lr}
0 & |x| \leq 0.1, \\
0.5 & 0.1<|x| \leq 0.54, \\
1 & |x|>0.54 .
\end{array} F_{n_{1}}(a)=\left\{\begin{array}{lr}
0 & |x| \leq 0.1 \\
0.5 & 0.1<|x| \leq 0.42 \\
1 & |x|>0.42 .
\end{array}\right.\right. \\
& F_{m_{2}}(a)=\left\{\begin{array}{lr}
0 & |x| \leq 0.1, \\
0.5 & 0.1<|x| \leq 0.32, \\
1 & |x|>0.32 .
\end{array} \quad F_{n_{2}}(a)=\left\{\begin{array}{lr}
0 & |x| \leq 0.1, \\
0.5 & 0.1<|x| \leq 0.39, \\
1 & |x|>0.39 .
\end{array}\right.\right. \\
& F_{m_{3}}(a)=\left\{\begin{array}{lr}
0 & |x| \leq 0.1, \\
0.5 & 0.1<|x| \leq 0.22, \\
1 & |x|>0.22 .
\end{array} F_{n_{3}}(a)=\left\{\begin{array}{lr}
0 & |x| \leq 0.1, \\
0.5 & 0.1<|x| \leq 0.28, \\
1 & |x|>0.28 .
\end{array}\right.\right. \\
& F_{m_{4}}(a)=\left\{\begin{array}{lr}
0 & |x| \leq 0.1, \\
0.5 & 0.1<|x| \leq 0.3, \\
1 & |x|>0.3 .
\end{array} F_{n_{4}}(a)=\left\{\begin{array}{lr}
0 & |x| \leq 0.1 \\
0.5 & 0.1<|x| \leq 0.18, \\
1 & |x|>0.18 .
\end{array}\right.\right. \\
& F_{m_{5}}(a)=\left\{\begin{array}{lr}
0 & |x| \leq 0.1 \\
0.5 & 0.1<|x| \leq 0.38, \\
1 & |x|>0.38 .
\end{array} \quad F_{n_{5}}(a)=\left\{\begin{array}{lr}
0 & |x| \leq 0.1 \\
0.5 & 0.1<|x| \leq 0.4 \\
1 & |x|>0.4 .
\end{array}\right.\right. \\
& F_{m_{6}}(a)=\left\{\begin{array}{lr}
0 & |x| \leq 0.1 \\
0.5 & 0.1<|x| \leq 0.24, \\
1 & |x|>0.24 .
\end{array} \quad F_{n_{6}}(a)=\left\{\begin{array}{lr}
0 & |x| \leq 0.1 \\
0.5 & 0.1<|x| \leq 0.2 \\
1 & |x|>0.2 .
\end{array}\right.\right. \\
& F_{m_{7}}(a)=\left\{\begin{array}{lr}
0 & |x| \leq 0.1, \\
0.5 & 0.1<|x| \leq 0.38, \\
1 & |x|>0.38 .
\end{array} F_{n_{7}}(a)=\left\{\begin{array}{lr}
0 & |x| \leq 0.1 \\
0.5 & 0.1<|x| \leq 0.3 \\
1 & |x|>0.3 .
\end{array}\right.\right.
\end{aligned}
$$


Step 6: The preference matrix for both membership and non-membership values are evaluated by the use of Table 2, and the aggregated intuitionistic fuzzy membership and non-membership preference matrix values are:

$$
\begin{aligned}
P_{M}^{v} & =\left(\begin{array}{ccccccc}
0 & 0.0320 & 0.2820 & 0.2820 & 0.0465 & 0.2820 & 0.1700 \\
0.2180 & 0 & 0.4520 & 0.2500 & 0.1205 & 0.0625 & 0 \\
0 & 0 & 0 & 0 & 0 & 0 & 0 \\
0.1205 & 0 & 0.2180 & 0 & 0.1205 & 0 & 0 \\
0 & 0.0160 & 0.3010 & 0.2500 & 0 & 0.2500 & 0.1235 \\
0.1205 & 0 & 0.1205 & 0.0640 & 0.1205 & 0 & 0 \\
0.1205 & 0.0320 & 0.3300 & 0.1585 & 0.1205 & 0.0945 & 0
\end{array}\right), \\
P_{M}^{v} & =\left(\begin{array}{ccccccc}
0 & 0 & 0 & 0 & 0.0640 & 0.0320 & 0 \\
0.1205 & 0 & 0 & 0.0160 & 0.0160 & 0 & 0 \\
0.2340 & 0.1875 & 0 & 0.0640 & 0.2850 & 0.0640 & 0.3315 \\
0.2905 & 0.1700 & 0 & 0 & 0.1615 & 0 & 0.2675 \\
0 & 0.1555 & 0.0320 & 0.0320 & 0 & 0.0320 & 0.1235 \\
0.3065 & 0.1700 & 0.0160 & 0.0160 & 0.0160 & 0 & 0.1700 \\
0 & 0 & 0.0320 & 0.0160 & 0.0800 & 0.0320 & 0
\end{array}\right) .
\end{aligned}
$$

Then, the aggregated intuitionistic fuzzy preference matrix is

$$
P^{v}=\left(\begin{array}{ccccccc}
0 & 0.0160 & 0.1410 & 0.1410 & 0.0553 & 0.1570 & 0.0850 \\
0.1693 & 0 & 0.2260 & 0.1330 & 0.0683 & 0.0313 & 0 \\
0.1170 & 0.0938 & 0 & 0.0320 & 0.1425 & 0.0320 & 0.1657 \\
0.2055 & 0.0850 & 0.1090 & 0 & 0.1410 & 0 & 0.1337 \\
0 & 0.0857 & 0.1665 & 0.1410 & 0 & 0.1410 & 0.1235 \\
0.2135 & 0.0850 & 0.0683 & 0.0400 & 0.0683 & 0 & 0.0850 \\
0.0602 & 0.0160 & 0.1810 & 0.0872 & 0.1003 & 0.0633 & 0
\end{array}\right) .
$$

Step 7: The preference matrix is outranked, while using Theorem 2, and the positive, negative, and net flows are in the proper form. See Table 6. Then, the preference is determined in the non-decreasing order. Thus, the preference structure is obtained as $D_{1}>D_{5}>D_{2}>D_{7}>D_{6}>D_{4}>D_{3}$.

Table 6. Outranking results derived by Algorithm.

\begin{tabular}{cccc}
\hline $\mathbf{X}$ & $\mathbf{\Psi}_{+}^{v}$ & $\mathbf{\Psi}_{-}^{v}$ & $\mathbf{\Psi}^{\boldsymbol{v}}$ \\
\hline$D_{1}$ & 0.8118 & 0.5699 & 0.2419 \\
$D_{2}$ & 0.6246 & 0.4237 & 0.2009 \\
$D_{3}$ & 0.3466 & 0.8685 & -0.5219 \\
$D_{4}$ & 0.4971 & 0.9071 & -0.4100 \\
$D_{5}$ & 0.763 & 0.5355 & 0.2275 \\
$D_{6}$ & 0.5741 & 0.6795 & -0.1054 \\
$D_{7}$ & 0.6841 & 0.5293 & 0.1548 \\
\hline
\end{tabular}

Step 8: By Definition 6, an account of SWIFA operator, the score values are evaluated and demonstrated in Table 7. Then, the graphical representation of score values is in Figure 5. 
Table 7. Aggregated preference and score values on the bases of SWIFA operator.

\begin{tabular}{ccc}
\hline $\mathbf{X}$ & AIFPVs & $s\left(G_{\tilde{v}}\left(\boldsymbol{B}_{\boldsymbol{i}}\right)\right)$ \\
\hline$D_{1}$ & $(0.5178,0.3313)$ & 0.1865 \\
$D_{2}$ & $(0.4730,0.3430)$ & 0.1300 \\
$D_{3}$ & $(0.3001,0.4688)$ & -0.1687 \\
$D_{4}$ & $(0.2947,0.4435)$ & -0.1487 \\
$D_{5}$ & $(0.4975,0.3476)$ & 0.1500 \\
$D_{6}$ & $(0.3341,0.4523)$ & -0.1182 \\
$D_{7}$ & $(0.4767,0.3319)$ & 0.1448 \\
\hline
\end{tabular}

Step 9: By the use of lexicographic order, score function and accuracy function related resultant and membership and non-membership grade-based preference structure are ranked, which follows the calculation in Table 7, and the AIFPV's are graphically illustrated, which visually shows the graphical results, with the help of Wei's maximizing deviation method and Extended PROMETHEE-II method's net flow resultant and score values of SWIFA operator. The ranking results of different methods are shown in Table 8.

Table 8. Preference structure given by various methods.

\begin{tabular}{cl}
\hline Techniques & Preference Structure of the Alternatives \\
\hline Algorithm (Wei) & $D_{1}>D_{5}>D_{7}>D_{2}>D_{6}>D_{4}>D_{3}$ \\
\hline Algorithm $($ PROMETHEE-II) & $D_{1}>D_{5}>D_{2}>D_{7}>D_{6}>D_{4}>D_{3}$ \\
\hline SWIFA with $\leq_{(s, m)}$ & $D_{1}>D_{5}>D_{7}>D_{2}>D_{6}>D_{4}>D_{3}$ \\
\hline SWIFA with $\leq_{(s, n)}$ & $D_{1}>D_{5}>D_{7}>D_{2}>D_{6}>D_{4}>D_{3}$ \\
\hline SWIFA with $\leq_{(m, n)}$ & $D_{1}>D_{5}>D_{7}>D_{2}>D_{6}>D_{4}>D_{3}$ \\
\hline SWIFA with $\leq_{(n, m)}$ & $D_{3}>D_{6}>D_{4}>D_{2}>D_{5}>D_{7}>D_{1}$ \\
\hline
\end{tabular}

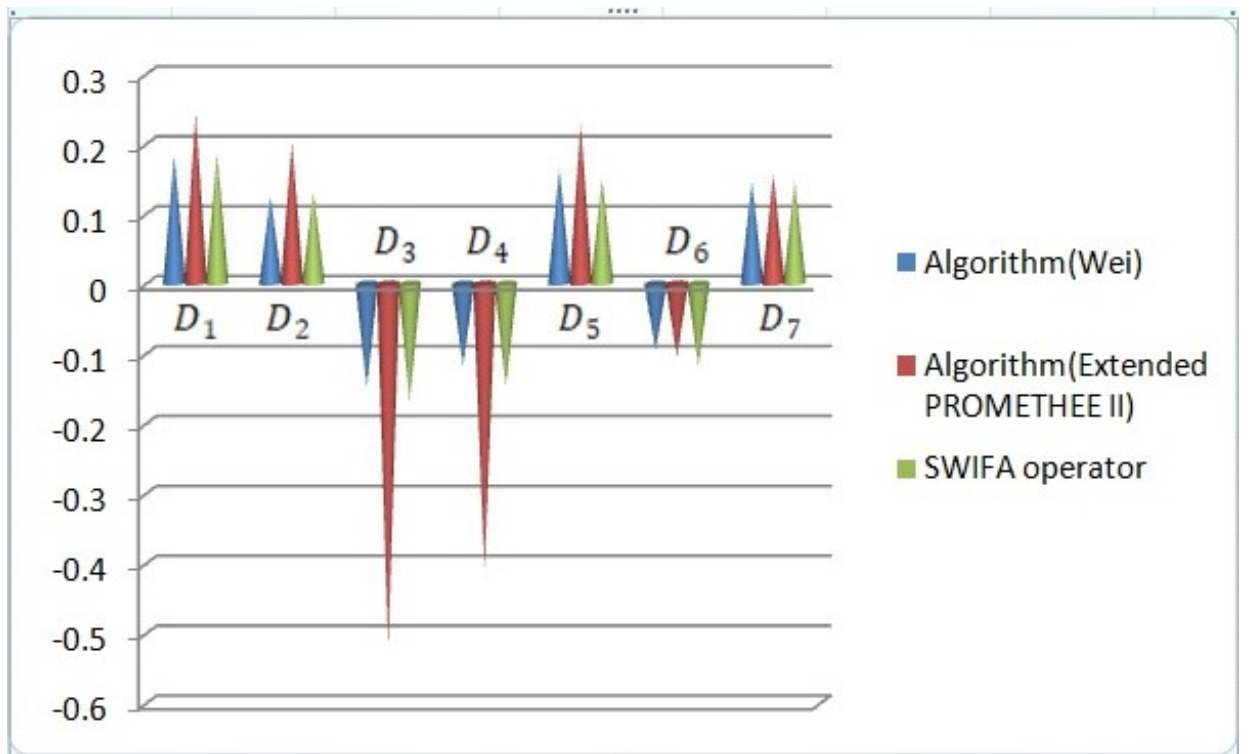

Figure 5. The graphical demonstration of ranking results. 


\section{Analysis}

\subsection{Comparison Analysis}

We compare the Extended PROMETHEE-II method with TOPSIS, IF-VIKOR, and EDAS methods. IFVs are derived from the hypothesis according to the criteria. Compared to the proposed method, the handling of criteria is distinct in each method, and the weight of each criteria is determined using Wei's method. Then, the existing procedures of the TOPSIS [10], IF-VIKOR [11], and EDAS [13] methods are explained in Figure 6. Finally, the ranking order is summarized in Table 9 and it clearly shows that the Extended PROMETHEE-II method is more suitable for this particular application when compared to these pre-proposed methods. The feasibility of the methods is depicted in Figure 7, indicating the accuracy of the Extended PROMETHEE method. From the graphical illustration, the Extended PROMETHEE-II demonstrates criteria that specify its optimality in detail.

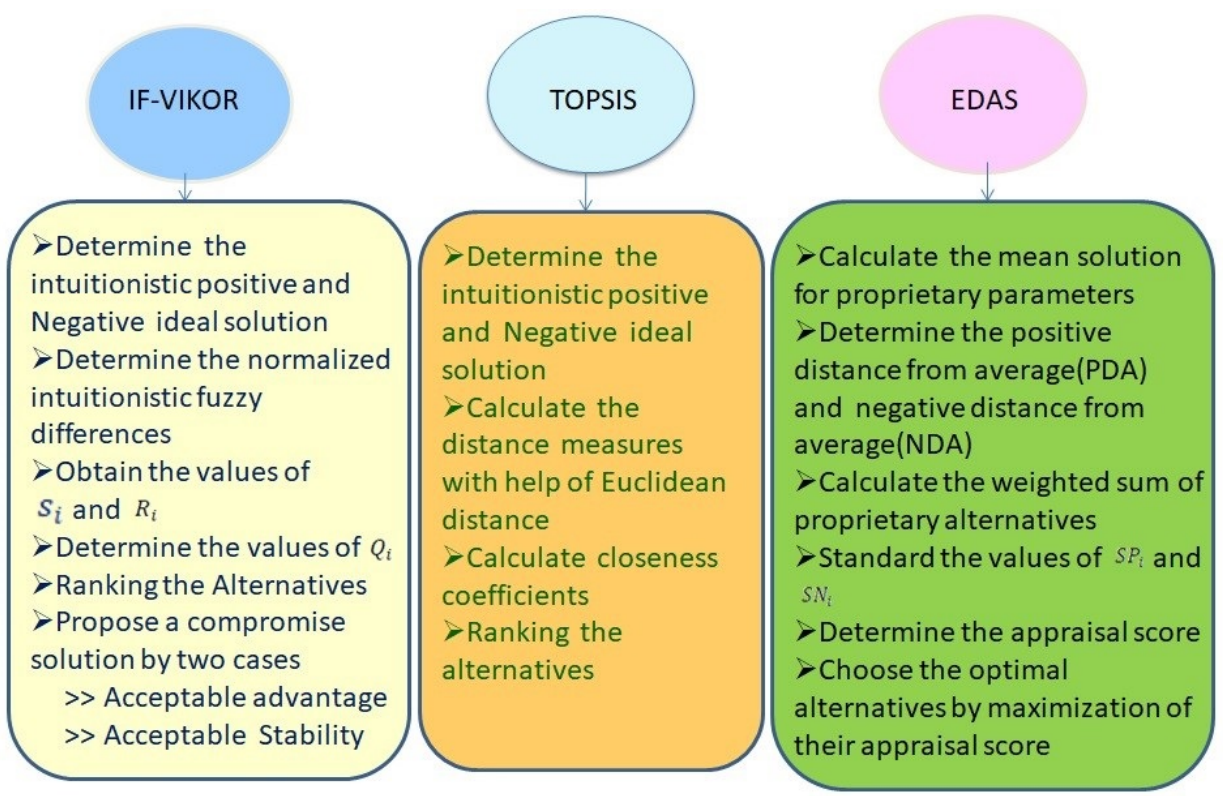

Figure 6. Procedures of IF-VIKOR, TOPSIS, and EDAS methods for ranking the alternatives.

Table 9. The comparison of TOPSIS, IF-VIKOR, and EDAS methods with Extended PROMETHEEII method.

\begin{tabular}{cccc}
\hline TOPSIS Method & IF-VIKOR Method & EDAS Method & PROPOSED Method \\
\hline 0.5299 & 0.0677 & 1 & 0.2419 \\
0.6095 & 0.4773 & 0.2867 & 0.2009 \\
0.5148 & 0.9049 & 0.2135 & -0.5219 \\
0.4643 & 0.7709 & 0 & -0.4100 \\
0.5355 & 0 & 0.6949 & 0.2275 \\
0.4801 & 0.9573 & 0.1149 & -0.1054 \\
0.5903 & 0.7541 & 0.4477 & 0.1548 \\
\hline
\end{tabular}




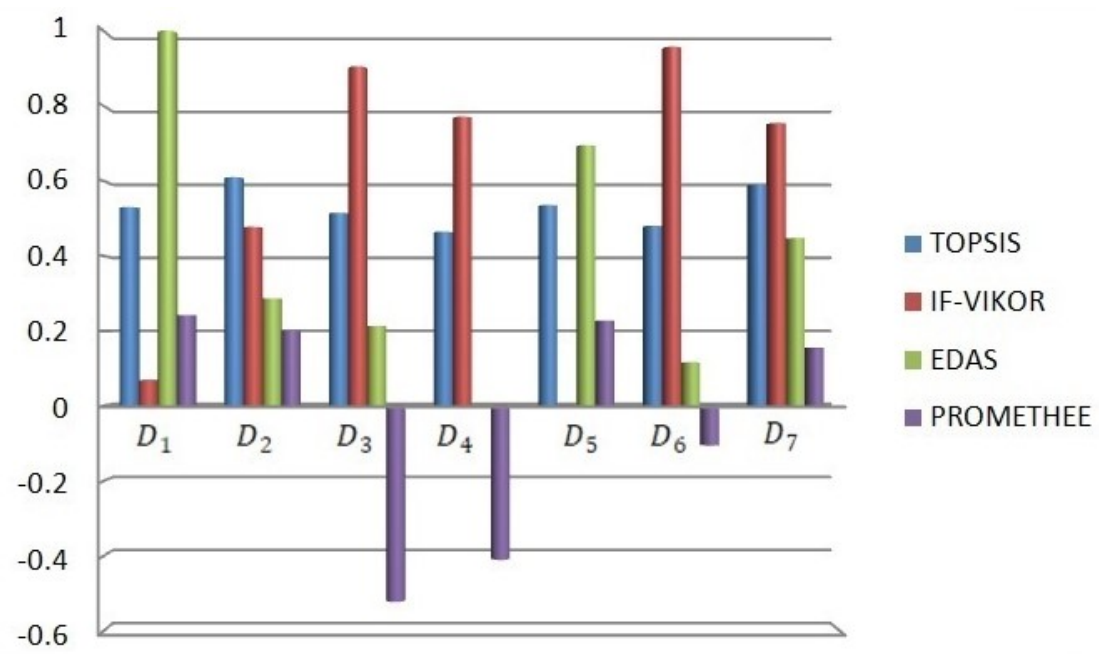

Figure 7. The comparison between the existing and proposed methods.

\subsection{Sensitivity Analysis}

We distinguish specific perspectives for the sensitivity analysis of the preference structure. When looking for AIFVs, we take a different approach. The weighted average of the diseased people's health is 7:3 in terms of the two phases of parameters. As a result, in the first case, the measurements based on the beneficial and non-beneficial criteria in the ratio are equal, and, in the second case, the weighting based on the beneficial and non-beneficial criteria in the ratio are twisted. With this, the preference structure is formed by the hypothesis. Finally, the result shows that the decision information is sensible; thus, the sensitivity level is graphically demonstrated.

Case 1: Generally, diseased people's health and well-being are in poor condition. Assume that, on a weighted average, the health condition and environment are equal in terms of beneficial and non-beneficial criteria.

The diagrammatic representation of Figure 8 depicts the Case 1 ranking results. The ranking results of the existing and proposed methods in comparison are in Table 9. Based on the Wei's maximizing deviation method, score and accuracy function are derived in Table 10 .

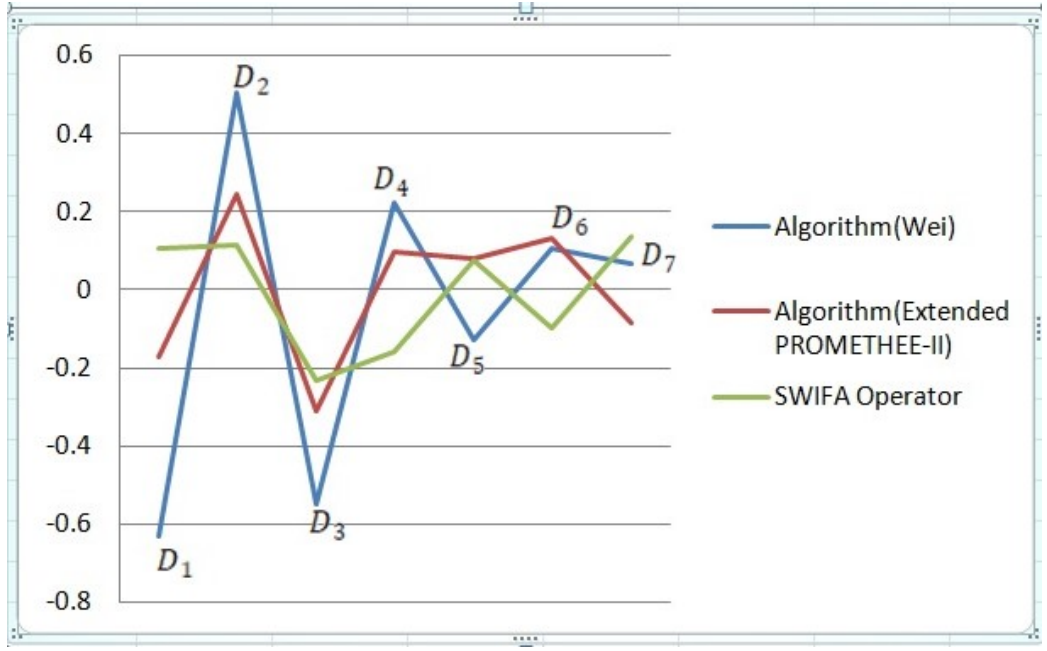

Figure 8. Graphical representation of sensibleness of the alternatives from Case 1. 
Table 10. Sensitivity analysis of AIFPVs and related measures by Case 1.

\begin{tabular}{cccc}
\hline $\mathbf{X}$ & AIFPVs & $s\left(G_{\tilde{v}}\left(\boldsymbol{B}_{\boldsymbol{i}}\right)\right)$ & $\boldsymbol{h}\left(\boldsymbol{G}_{\tilde{\boldsymbol{v}}}\left(\boldsymbol{B}_{\boldsymbol{i}}\right)\right)$ \\
\hline$D_{1}$ & $(0.3712,0.4903)$ & -0.1191 & 0.8615 \\
$D_{2}$ & $(0.1396,0.7760)$ & -0.6364 & 0.9156 \\
$D_{3}$ & $(0.5367,0.1597)$ & 0.3770 & 0.6964 \\
$D_{4}$ & $(0.4478,0.2438)$ & 0.2041 & 0.6916 \\
$D_{5}$ & $(0.2548,0.6259)$ & -0.3711 & 0.8806 \\
$D_{6}$ & $(0.4867,0.2476)$ & 0.2390 & 0.7343 \\
$D_{7}$ & $(0.0989,0.8368)$ & $-0,7379$ & 0.9357 \\
\hline
\end{tabular}

The Extended PROMETHEE approach is used for proposing the sensitive case. After the determination of the threshold values, the positive flow of the approach is evaluated using Equations (4) and (5), negative flow determined using Equations (9) and (10), and net flows follow Definition 9. Finally, these are shown in Table 11.

Table 11. Sensitivity of positive, negative, and net flows by Case 1.

\begin{tabular}{cccc}
\hline $\mathbf{X}$ & $\boldsymbol{\Psi}_{+}^{v}$ & $\boldsymbol{\Psi}_{-}^{v}$ & $\boldsymbol{\Psi}^{v}$ \\
\hline$D_{1}$ & 0.6023 & 0.5686 & 0.0337 \\
$D_{2}$ & 0.5182 & 0.3334 & 0.1848 \\
$D_{3}$ & 0.217 & 0.9611 & -0.7441 \\
$D_{4}$ & 0.488 & 0.5219 & -0.0339 \\
$D_{5}$ & 0.5698 & 0.4677 & 0.1021 \\
$D_{6}$ & 0.4031 & 0.5872 & -0.1841 \\
$D_{7}$ & 0.8773 & 0.2358 & 0.6415 \\
\hline
\end{tabular}

On the basis of the SWIFA operator in Definition 6, vaccine prioritization structure is initiated for determining the ranking in Case 1, and it is demonstrated in Table 12.

Table 12. AIFPVs and SWIFA operator and scores for sensibleness analyzation using Case 1.

\begin{tabular}{ccc}
\hline $\mathbf{X}$ & AIFPVs & $s\left(G_{\tilde{v}}\left(\boldsymbol{B}_{\boldsymbol{i}}\right)\right)$ \\
\hline$D_{1}$ & $(0.3777,0.3838)$ & -0.0061 \\
$D_{2}$ & $(0.3867,0.4082)$ & -0.0215 \\
$D_{3}$ & $(0.2363,0.3999)$ & -0.1636 \\
$D_{4}$ & $(0.3127,0.4442)$ & -0.1315 \\
$D_{5}$ & $(0.3663,0.4174)$ & -0.0511 \\
$D_{6}$ & $(0.2971,0.4139)$ & -0.1168 \\
$D_{7}$ & $(0.4502,0.3932)$ & 0.0570 \\
\hline
\end{tabular}

Case 2: Consider the diseased people's health conditions and their social environment. Based on the beneficial and non-beneficial criteria, the weighted average is twisted. The graphical illustration of Case 2 is in Figure 9. 


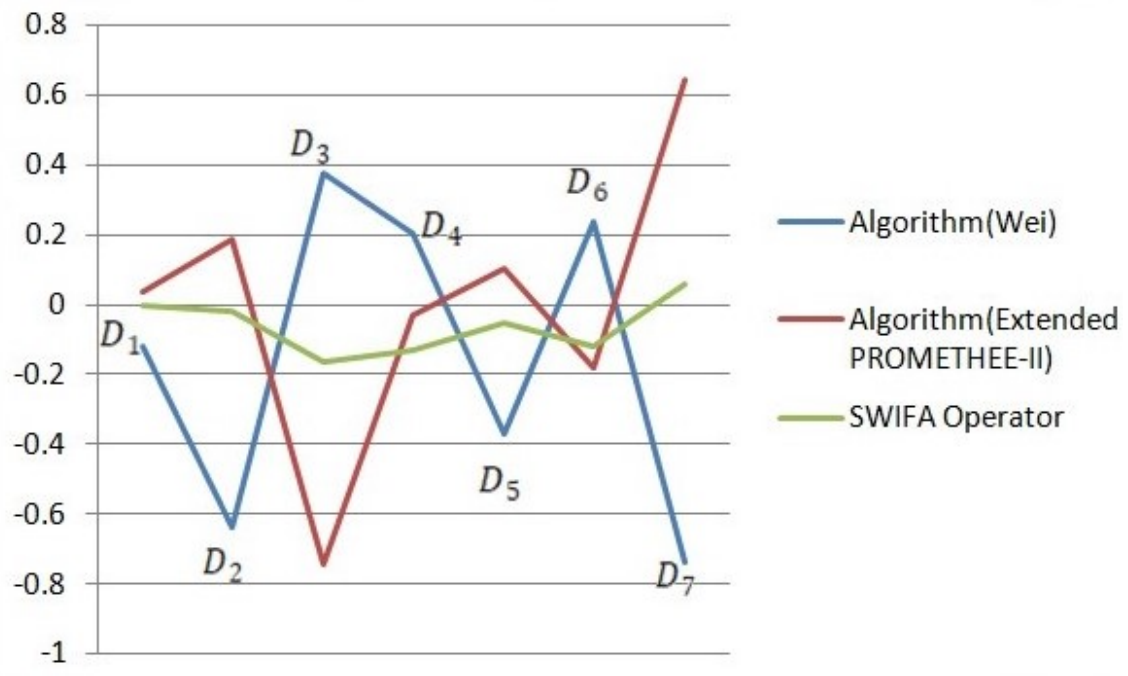

Figure 9. Graphical illustration of sensitivity analysis from Case 2.

The sensitivity analysis of AIFPVs and related measures are done in Case 2. On the basis of Wei's maximizing deviation method, score and accuracy function are derived in Table 13.

Table 13. Sensitivity analysis of AIFPVs and related measures by Case 2.

\begin{tabular}{cccc}
\hline $\mathbf{X}$ & AIFPVs & $s\left(G_{\tilde{v}}\left(\boldsymbol{B}_{\boldsymbol{i}}\right)\right)$ & $\boldsymbol{h}\left(\boldsymbol{G}_{\tilde{v}}\left(\boldsymbol{B}_{\boldsymbol{i}}\right)\right)$ \\
\hline$D_{1}$ & $(0.1490,0.7804)$ & -0.6314 & 0.9295 \\
$D_{2}$ & $(0.6646,0.1584)$ & 0.5062 & 0.8230 \\
$D_{3}$ & $(0.1426,0.6929)$ & -0.5503 & 0.8355 \\
$D_{4}$ & $(0.4575,0.2337)$ & 0.2239 & 0.6912 \\
$D_{5}$ & $(0.3613,0.4894)$ & -0.1282 & 0.8507 \\
$D_{6}$ & $(0.4236,0.3156)$ & 0.1080 & 0.7392 \\
$D_{7}$ & $(0.4399,0.3710)$ & 0.0689 & 0.8109 \\
\hline
\end{tabular}

The Extended PROMETHEE approach is used for proposing the sensitive case. The positive flow of the approach is evaluated using Equations (4) and (5), negative flow follows the Equations (9) and (10), and net flows are found using Definition 9. All are shown in Table 14.

Table 14. Sensitivity of positive, negative, and net flows by Case 2.

\begin{tabular}{cccc}
\hline $\mathbf{X}$ & $\boldsymbol{\Psi}_{+}^{v}$ & $\boldsymbol{\Psi}_{-}^{v}$ & $\boldsymbol{\Psi}^{\boldsymbol{v}}$ \\
\hline$D_{1}$ & 0.5953 & 0.7655 & -0.1702 \\
$D_{2}$ & 0.6279 & 0.3815 & 0.2464 \\
$D_{3}$ & 0.583 & 0.8918 & -0.3088 \\
$D_{4}$ & 0.6742 & 0.5742 & 0.1 \\
$D_{5}$ & 0.6577 & 0.5757 & 0.082 \\
$D_{6}$ & 0.5601 & 0.4246 & 0.1355 \\
$D_{7}$ & 0.508 & 0.5929 & -0.0849 \\
\hline
\end{tabular}

By the use of SWIFA operator in Definition 6, vaccine prioritization structure is initiated for suggesting the ranking in Case 2, and it is described in Table 15. 
Table 15. AIFPVs and SWIFA operator and scores for sensibleness analyzation using Case 1.

\begin{tabular}{ccc}
\hline $\mathbf{X}$ & AIFPVs & $s\left(G_{\tilde{v}}\left(\boldsymbol{B}_{\boldsymbol{i}}\right)\right)$ \\
\hline$D_{1}$ & $(0.4416,0.3358)$ & 0.1058 \\
$D_{2}$ & $(0.4660,0.3526)$ & 0.1134 \\
$D_{3}$ & $(0.2625,0.4942)$ & -0.2317 \\
$D_{4}$ & $(0.3244,0.4805)$ & -0.1561 \\
$D_{5}$ & $(0.4393,0.3613)$ & 0.0780 \\
$D_{6}$ & $(0.3552,0.4514)$ & -0.0962 \\
$D_{7}$ & $(0.4526,0.3154)$ & 0.1372 \\
\hline
\end{tabular}

\section{Conclusions and Future Work}

In the COVID-19 pandemic situation, clinical experts advised that older people and frontline personnel require vaccination primarily. Nevertheless, younger people with pre-existing diseases are also in infectious situations. The study considers that younger people with COVID-19 comorbidities and other chronic diseases are also at a higher risk of the COVID-19 pandemic escalating the account of the severity of the disease. People of young age with COVID-19 comorbidities and chronic diseases are definitely in need of vaccination, according to the preference structure. So, in addition to prioritization, the infected younger people's information is used in the MCDM technique, and the ambiguity is removed using the IFSS environment. Then, with the help of Wei's maximizing deviation method, the weight vector of each criterion is evaluated. The aggregation of the alternatives is calculated by several operators. The aggregated IFVs are derived from two situations:

1. the people who have COVID-19 comorbidities; and

2. the people who have chronic diseases with COVID-19.

Then, the outranking is done under the Extended PROMETHEE-II method.

The solution for the priority structure according to the Extended PROMETHEE-II process in IFSS is listed in Table 8. The priority method in examining the condition of young people suffering from chronic diseases suggests to recommend vaccination for Alzheimer's patients at first. Once their immune response is confirmed, the preferred system for vaccination should be recommended for obese people, diabetics, and those with high blood pressure, in that order. Finally, adolescents with lung, heart, and kidney injuries are recommended to be vaccinated depending on the severity of the vaccine. This result is numerically derived, and preferences are ranked by the utilization of lexicographic order, and it shows the optimality of the preference structure using Extended PROMETHEEII. PROMETHEE methods may only be applied if the decision-maker can express his preference between two actions on a given criterion on a ratio scale. In IFSS, there is a potential hypothesis that $m_{B}(x)$ and $n_{B}(x)$ are independent. However, when people give the membership and non-membership degrees, it does make sense. The knowledge, experience, and emotional maturity of assessors support both the membership and nonmembership degrees.

PROMETHEE GAIA visualization and the complex intuitionistic fuzzy soft set environment are suggested for future work that give more satisfiable results in MCDM techniques, while the decider has hesitation in uncertain problems. Then, Spherical fuzzy soft set-based diagnostic approach is also proposed for future work.

Author Contributions: Conceptualization, S.N., S.P., and D.K.; Data curation, S.K.; Formal analysis, S.N., S.P., T.N.P. and D.K.; Investigation, S.N., S.P., J.V.K. and D.K.; Methodology, S.N., S.P., T.N.P., J.V.K. and D.K.; Resources, R.S. and P.N.; Supervision, S.N. and D.K.; Validation, S.N., S.K., R.S., P.N. and D.K.; Writing—original draft, S.N., S.P. and D.K.; Writing—review \& editing, S.N., J.V.K. and D.K. All authors have read and agreed to the published version of the manuscript.

Funding: This research received no external funding.

Acknowledgments: This work was supported by the National Research Foundation (NRF) of Korea Grant funded by the Korean Government (MSIT) (NRF- 2020S1A5A8044635). The authors would 
like to dedicate this work to all the health workers, volunteers and drug researchers who make sure that the humanity is protected.

Conflicts of Interest: The authors declare that there is no conflict of interest regarding this research work.

\section{Appendix A}

Many people in the world are affected some perennial diseases, such as cardiovascular disease, interstitial lung disease, renal disease, diabetes, blood pressure, obesity, and nerve disease, such as Alzheimer's. With the infection of COVID-19, these people are vulnerable with the comorbidity. During the second wave of coronavirus in India, youngsters aged 20-49 years are mostly affected by COVID-19. Right now, youngsters who have COVID-19 are in the deadly situation if they already have any of the chronic diseases. Among all the chronic diseases, the risk factor of Alzheimer's disease for youngsters is slightly low. Vaccination has some side effects, and it causes infection. Side effects and infection differ on account of chronically ill people's health condition. On account of the COVID-19 comorbidity and the information about the chronically ill people information, we may determine the vaccine prioritization structure. This information is tabulated in Appendix A.

Table A1. A brief survey of chronic diseases with COVID-19 comorbidities.

\begin{tabular}{|c|c|c|c|}
\hline Disease & Author & Study & Comorbidities \\
\hline \multirow{3}{*}{ Alzheimer's } & Marcello Ciaccio et al. [22] & $\begin{array}{l}\text { The study highlights the need to protect } \\
\text { Alzheimer's patients with dementia as part of } \\
\text { the strategy to control the COVID-19 pandemic. }\end{array}$ & $\begin{array}{l}\text { Respiratory illness, } \\
\text { Cardiovascular and renal } \\
\text { manifestation }\end{array}$ \\
\hline & QuanQiu Wang et al. [23] & $\begin{array}{l}\text { The relationship between the AD (Alzheimer's } \\
\text { Disease) and COVID-19 are observed, and, from } \\
\text { the review, we conclude that the COVID-19 } \\
\text { patients have a high risk of AD. }\end{array}$ & \\
\hline & Jinjun Ran et al. [24] & $\begin{array}{l}\text { Analyzation of the COVID-19 patient's blood } \\
\text { pressure variation is obtained. The report says } \\
\text { the standard deviations of systolic blood } \\
\text { pressure (SBP) and diastolic blood pressure } \\
\text { (DBP) were independently associated with } \\
\text { mortality and ICU admission. }\end{array}$ & $\begin{array}{c}\text { Chronic obstructive } \\
\text { pulmonary disease, Chronic } \\
\text { liver disease, Chronic kidney } \\
\text { disease }\end{array}$ \\
\hline
\end{tabular}

Blood Pressure

Songjiang Huang et al. [25]
The observational study compares the COVID-19 patients with hypertension and without hypertension. When compared to the without hypertension patients, the hypertension patients had a severe illness, such as pneumonia, excessive inflammatory reactions, organ and tissue damage, and deterioration of the disease. Hence, the high blood pressure patients could need excessive prevention because of their chronic condition.

\begin{tabular}{ccc} 
Thomas M Drake et al. & $\begin{array}{c}\text { The article suggests that COVID-19 with } \\
\text { interstitial lung disease patients need more } \\
\text { stringent precautions because, otherwise, it will } \\
\text { lead to an increase in the mortality rate. }\end{array}$ & $\begin{array}{c}\text { Chronic cardiac disease, } \\
\text { Lypertension, Diabetes }\end{array}$ \\
\cline { 2 - 3 } Ling Leng et al. [27] & $\begin{array}{c}\text { The lung injury due to COVID-19 has complex } \\
\text { pathophysiology. The COVID-19 interface which } \\
\text { stimulates the lung function negatively, and this } \\
\text { augments the morbidity and mortality. The } \\
\text { report also presents that the patients who have } \\
\text { lung injury with COVID-19 are definitely in a } \\
\text { critical situation in their entire lifeline. }\end{array}$ \\
renal disease, Lung infection
\end{tabular}

Coronary heart disease,

Cerebrovascular disease, Diabetes, Cancer 
Table A2. A brief survey of chronic diseases with COVID-19 comorbidities.

\begin{tabular}{|c|c|c|c|}
\hline Disease & Author & Study & Comorbidities \\
\hline \multirow[b]{2}{*}{ Heart disease } & Sung Bae et al. [28] & $\begin{array}{l}\text { Age-wise risk factors of cardiovascular } \\
\text { disease are considered. Patients with the } \\
\text { Cardio Vascular Disease have severe risk } \\
\text { with any age. But, the prevalence is most in } \\
\text { the patients who reach elder age. }\end{array}$ & $\begin{array}{l}\text { Diabetes, hypertension, renal } \\
\text { injury, Myocardial injury, } \\
\text { arrhythmia }\end{array}$ \\
\hline & Kamna Srivastava [29] & $\begin{array}{l}\text { The cardiac diseases have severe mortality } \\
\text { and morbidity rate due to the COVID-19 } \\
\text { pandemic. The clinical expert suggested } \\
\text { analyzing the vaccination and several types } \\
\text { of treatment ideology. If is found that } \\
\text { molecular targets and clinical presentation } \\
\text { solve the COVID-19 spread. }\end{array}$ & $\begin{array}{l}\text { acute coronary syndrome and } \\
\text { venous thromboembolism }\end{array}$ \\
\hline \multirow{2}{*}{ Obesity } & Yanan Chu et al. [30] & $\begin{array}{l}\text { The study reviews the effect of obesity on the } \\
\text { severity of COVID-19 and the increased rate } \\
\text { of obesity in need of ICU and IVM support. } \\
\text { The younger patients with high BMI need } \\
\text { more precaution. }\end{array}$ & $\begin{array}{l}\text { Severe illness, Diabetes, and } \\
\text { other comorbidities }\end{array}$ \\
\hline & Zhu et al. [31] & $\begin{array}{l}\text { The vulnerability of SARS-COV- } 2 \text { infection } \\
\text { increase by obesity. Obesity patients require } \\
\text { more attention to minimize the mortality rate } \\
\text { due to COVID-19 cases. }\end{array}$ & \\
\hline
\end{tabular}

The COVID-19 patient's prognosis factor about Chronic kidney disease is unknown. The clinical experts collect the information regarding hospitalized patients with Chronic Michael Hultstrom et al. [32] Kidney Disease and without Chronic Kidney Disease. The clinical information results from the CKD patients inform that they had a higher mortality rate.

Chronic kidney disease (CKD) People with kidney disease have been
Diabetes, hypertension, chronic obstructive pulmonary disease, Chronic illness, cardiovascular disease severely affected by COVID-19 with high rates of severe infection, critical illness, and death. The renal community welcomes the

ERA-EDTA council [33] imminent arrival of effective COVID-19 vaccines. The COVID-19 pandemic has a significant impact on people who have kidney transplants or are awaiting a kidney transplant.

The systematic review and meta-analysis prioritize to collect the diabetes patients' information and evidently show the patient's diabetes severity level and mortality rate. The suggestion includes the best prevention function and evidence-based treatments.
Hyperglycammia, hypertension, and some other comorbidities
Diabetes

Hartmann-Boyce et al. [35]
The need for conclusive measure fabricates a tension when evidence is insufficient. The detailed review of the research proposes diabetes patients have increased risk of COVID-19, and chronically diseased people need high preference. 


\section{References}

1. Summary, E. WHO SAGE Values Framework for the Allocation and Prioritization of COVID-19 Vaccination; WHO: Geneva, Switzerland, 2020; pp. 1-13.

2. Dooling, K. COVID-19 Vaccine Prioritization: Work Group Considerations ACIP COVID-19 Vaccines Work Group; Vaccines Work Group: Atlanta, GA, USA, 2020.

3. Bubar, KM.; Kissler, SM.; Lipsitch, M.; Cobey, S.; Grad, Y.H.; Larremore, D.B. Model-informed COVID-19 vaccine prioritization strategies by age and serostatus. Science 2020, 371, 916-921. [CrossRef] [PubMed]

4. Ishizaka, A.; Nemery, P. Multi-Criteria Decision Analysis: Methods and Software; Wiley: West Sussex, UK, 2013.

5. Zadeh, L.A. Fuzzy sets. Inf. Control 1965, 8, 338-353. [CrossRef]

6. Molodtsov, D.A. Soft set theory-First results. Comput. Math. Appl. 1999, 37, 19-31. [CrossRef]

7. Maji, P.K.; Biswas, R.; Roy, A.R. Fuzzy soft sets. J. Fuzzy Math. 2001, 9, 589-602.

8. Atanassov, K.T. Intuitionistic fuzzy sets. Fuzzy Sets Syst. 1986, 20, 87-96. [CrossRef]

9. Maji, P.K.; Biswas, R.; Roy, A.R. Intuitionistic fuzzy soft sets. J. Fuzzy Math. 2001, 9, 677-692.

10. Onat, N.C.; Gumus, S.; Kucukvar, M.; Tatari, O. Application of the TOPSIS and intuitionistic fuzzy set approaches for ranking the life cycle sustainability performance of alternative vehicle technologies. Sustain. Prod. Consum. 2016, 6, 12-25. [CrossRef]

11. Zhao, J.; You, X.Y.; Liu, H.C.; Wu, S.M. An Extended VIKOR Method Using Intuitionistic Fuzzy Sets and Combination Weights for Supplier Selection. Symmetry 2017, 9, 169. [CrossRef]

12. Feng, F.; Xu, Z.; Fujita, H.; Liang, M. Enhancing PROMETHEE method with intuitionistic fuzzy soft sets. Int. J. Intell. Syst. 2020, 35, 1071-1104. [CrossRef]

13. Peng, X. Some Novel Decision Making Algorithms for Intuitionistic Fuzzy Soft Set. J. Intell. Fuzzy Syst. 2019, 37, 1327-1341. [CrossRef]

14. Hezam, I.M.; khan Nayeem, M.; Foul, A.; Alrasheedi, A.F. COVID-19 Vaccine: A Neutrosophic MCDM Approach for Determining the Priority Groups. Results Phys. 2020, 20, 103654. [CrossRef]

15. Chen, S.M.; Tan, J.M. Handling multicriteria fuzzy decision-making problems based on vague set theory. Fuzzy Sets Syst. 1994, 67, 163-172. [CrossRef]

16. Hong, D.H.; Choi, C.H. Multi-criteria fuzzy decision-making problems based on vague set theory. Fuzzy Sets Syst. 2000, 114, 103-113. [CrossRef]

17. Yager, R.R. Multicriteria decision making with ordinal/linguistic intuitionistic fuzzy sets for mobile apps. IEEE Trans. Fuzzy Syst. 2016, 24, 590-599. [CrossRef]

18. Wei, G.W. Maximizing deviation method for multiple attribute decision making in intuitionistic fuzzy setting. Knowl.-Based Syst. 2008, 21, 833-836. [CrossRef]

19. Xu, Z.S. Intuitionistic fuzzy aggregation operators. IEEE Trans. Fuzzy Syst. 2007, 15, 1179-1187.

20. Feng, F.; Liang, M.; Fujita, H.; Yager, R.R.; Liu, X. Lexicographic orders of intuitionistic fuzzy values and their relationships. Mathematics 2019, 7, 166. [CrossRef]

21. Xu, Z.S.; Yager, R.R. Intuitionistic and interval-valued intutionistic fuzzy preference relations and their measures of similarity for the evaluation of agreement within a group. Fuzzy Optim. Decis. Mak. 2009, 8, 123-139. [CrossRef]

22. Ciaccio, M.; Lo Sasso, B.; Scazzone, C.; Gambino, C.M.; Ciaccio, A.M.; Bivona, G.; Piccoli, T.; Giglio, R.V.; Agnello, L. COVID-19 and Alzheimer's Disease. Brain Sci. 2021, 113, 305. [CrossRef]

23. Wang, Q.; Davis, P.B.; Gurney, M.E.; Xu, R. COVID-19 and dementia: Analyses of risk, disparity, and outcomes from electronic health records in the US. Alzheimers Dement 2021.10.1002/alz.12296. [CrossRef]

24. Ran, J.; Song, Y.; Zhuang, Z.; Han, L.; Zhao, S.; Cao, P.; Geng, Y.; Xu, L.; Qin, J.; He, D.; et al. Blood pressure control and adverse outcomes of COVID-19 infection in patients with concomitant hypertension in Wuhan, China. Hypertens. Res. 2020, 43, 1267-1276. [CrossRef]

25. Huang, S.; Wang, J.; Liu, F.; Liu, J.; Cao, G.; Yang, C.; Liu, W.; Tu, C.; Zhu, M.; Xiong, B. COVID-19 patients with hypertension have more severe disease: A multicenter retrospective observational study. Hypertens. Res. 2020, 43, 824-831. [CrossRef]

26. Drake, T.M.; Docherty, A.B.; Harrison, E.M.; Quint, J.K.; Adamali, H.; Agnew, S.; Babu, S.; Barber, C.M.; Barratt, S.; Bendstrup, E.; et al. Outcome of Hospitalization for COVID-19 in Patients with Interstitial Lung Disease: An International Multicenter Study. Am. J. Respir. Crit. Care Med. 2020, 202, 1656-1665. [CrossRef]

27. Leng, L.; Cao, R.; Ma, J.; Mou, D.; Zhu, Y.; Li, W.; Lv, L.; Gao, D.; Zhang, S.; Gong, F.; et al. Pathological features of COVID-19associated lung injury: A preliminary proteomics report based on clinical samples. Signal Transduct. Target. Ther. 2020, 5, 240. [CrossRef]

28. Bae, S.; Kim, S.R.; Kim, M.N.; Shim, W.J.; Park, S.M. Impact of cardiovascular disease and risk factors on fatal outcomes in patients with COVID-19 according to age: A systematic review and meta-analysis. Heart 2020, 107, 373-80. [CrossRef] [PubMed]

29. Srivastava, K. Association between COVID-19 and cardiovascular disease. Int. J. Cardiol. Heart Vasc. 2020, 29, 100583. [CrossRef] [PubMed]

30. Chu, Y.; Yang, J.; Shi, J.; Zhang, P.; Wang, X. Obesity is associated with increased severity of disease in COVID-19 pneumonia: A systematic review and meta-analysis. Eur. J. Med. Res. 2020, 25. [CrossRef] [PubMed]

31. Zhu, X.; Yang, L.; Huang, K. COVID-19 and Obesity: Epidemiology, Pathogenesis and Treatment. Diabetes Metab. Syndr. Obes. 2020, 13, 4953-4959. [CrossRef] [PubMed] 
32. Hultström, M.; Lipcsey, M.; Wallin, E.; Larsson, I.M.; Larsson, A.; Frithiof, R. Severe acute kidney injury associated with progression of chronic kidney disease after critical COVID-19. Crit Care 2021, 25, 37. [CrossRef] [PubMed]

33. ERA-EDTA Council; ERACODA Working Group. Chronic kidney disease is a key risk factor for severe COVID-19: A call to action by the ERA-EDTA. Nephrol. Dial. Transplant. 2021, 36, 87-94. [CrossRef] [PubMed]

34. Abdi, A.; Jalilian, M.; Sarbarzeh, P.A.; Vlaisavljevic, Z. Diabetes and COVID-19: A systematic review on the current evidences. Diabetes Res. Clin. Pract. 2020, 166, 108347. [CrossRef] [PubMed]

35. Hartmann-Boyce, J.; Morris, E.; Goyder, C.; Kinton, J.; Perring, J.; Nunan, D.; Mahtani, K.; Buse, J.B.; Del Prato, S.; Ji, L.; et al. Diabetes and COVID-19: Risks, Management, and Learnings From Other National Disasters. Am. Diabetes Assoc. 2020, 43, 1695-1703. [CrossRef] [PubMed] 